\title{
Market Reaction to Mandatory Nonfinancial Disclosure
}

\section{Citation}

Grewal, Jody, Edward J. Riedl, and George Serafeim. "Market Reaction to Mandatory

Nonfinancial Disclosure." Harvard Business School Working Paper, No. 16-025, September 2015.

\section{Permanent link}

http://nrs.harvard.edu/urn-3:HUL.InstRepos:22565791

\section{Terms of Use}

This article was downloaded from Harvard University's DASH repository, and is made available under the terms and conditions applicable to Open Access Policy Articles, as set forth at http:// nrs.harvard.edu/urn-3:HUL.InstRepos:dash.current.terms-of-use\#OAP

\section{Share Your Story}

The Harvard community has made this article openly available.

Please share how this access benefits you. Submit a story.

\section{Accessibility}




\section{Market Reaction to Mandatory Nonfinancial Disclosure}

Jody Grewal

Edward J. Riedl

George Serafeim

Working Paper 16-025 


\title{
Market Reaction to Mandatory Nonfinancial Disclosure
}

\author{
Jody Grewal
}

Harvard Business School

Edward J. Riedl

Boston University

George Serafeim

Harvard Business School

Working Paper 16-025 


\title{
Market Reaction to Mandatory Nonfinancial Disclosure
}

\author{
Jody Grewal \\ Harvard Business School \\ Edward J. Riedl \\ Boston University \\ George Serafeim * \\ Harvard Business School
}

September 2015

\begin{abstract}
This paper examines the equity market reaction to events associated with the passage of a directive in the European Union (EU) mandating increased nonfinancial disclosure, which affected firms listed on EU exchanges or having significant operations in the EU. The mandated disclosures relate to firms' environmental, social, and governance performance. Using a crosscountry sample, we first document an on average negative market reaction to events increasing the likelihood of passage for this regulation, consistent with equity investors anticipating net costs with the directive's passage for most firms. Exploiting cross-sectional variation, we then predict and document a more negative market reaction for firms having: (i) low pre-directive nonfinancial disclosure levels, consistent with investors anticipating these future disclosures to reveal worse-than-expected news; (ii) weaker performance on nonfinancial issues, consistent with expectations for these firms to incur future costs to internalize current externalities; and (iii) lower ownership by institutional asset owners, consistent with such investors demanding further disclosures than mandated by the directive. The average market reaction for firms with superior nonfinancial performance and disclosure in our sample is positive, suggesting that investors expect net benefits from the passage of the directive for these firms.
\end{abstract}

Key Words: event study; ESG reporting; international; nonfinancial disclosure; sustainability; environmental; social responsibility; governance

Acknowledgments: We thank the following for useful comments and discussion: Bob Eccles, Alan Jagolinzer, Janine Maniora, Estelle Sun, and Tingting Ye.

* Corresponding Author:

381 Morgan Hall

Boston, MA

gserafeim@hbs.edu 


\title{
Market Reaction to Mandatory Nonfinancial Disclosure
}

\begin{abstract}
This paper examines the equity market reaction to events associated with the passage of a directive in the European Union (EU) mandating increased nonfinancial disclosure, which affected firms listed on EU exchanges or having significant operations in the EU. The mandated disclosures relate to firms' environmental, social, and governance performance. Using a crosscountry sample, we first document an on average negative market reaction to events increasing the likelihood of passage for this regulation, consistent with equity investors anticipating net costs with the directive's passage for most firms. Exploiting cross-sectional variation, we then predict and document a more negative market reaction for firms having: (i) low pre-directive nonfinancial disclosure levels, consistent with investors anticipating these future disclosures to reveal worse-than-expected news; (ii) weaker performance on nonfinancial issues, consistent with expectations for these firms to incur future costs to internalize current externalities; and (iii) lower ownership by institutional asset owners, consistent with such investors demanding further disclosures than mandated by the directive. The average market reaction for firms with superior nonfinancial performance and disclosure in our sample is positive, suggesting that investors expect net benefits from the passage of the directive for these firms.
\end{abstract}

Key Words: event study; ESG reporting; international; nonfinancial disclosure; sustainability; environmental; social responsibility; governance 


\section{INTRODUCTION}

This study investigates the equity market reaction to events associated with the adoption

of mandatory nonfinancial disclosure. Specifically, we examine the passage of European Union (EU) Directive 2014/95 on disclosure of nonfinancial information. This directive requires affected companies to disclose in their annual management report information on policies, risks, and outcomes regarding environmental matters, social and employee aspects, respect for human rights, anticorruption and bribery issues, and diversity in their board of directors. The directive applies to firms either (i) listed on EU exchanges or having significant operations in the EU, (ii) defined to be "large" (i.e., having 500 or more employees), or (iii) designated as public-interest entities by EU Member States due to the nature of their activities, size, or number of employees. This directive is intended to provide investors and other stakeholders with a more comprehensive picture of firm performance.

We assess the equity market's perception of the anticipated net costs or benefits associated with this directive by investigating the market reaction to three key events associated with its adoption. Following prior research employing event study methodology to market-wide regulation (e.g., Zhang 2007; Armstrong et al. 2010), our dependent variable is the firm's cumulative five-day abnormal stock return, centered on the event dates, and aggregated across the three sample events. To isolate market effects attributable to the directive, we adjust our treatment firms' stock return with a comparable return for control firms, identified via a matching algorithm using the same country and sector, and having the nearest congruence in size and price-to-book ratio. Thus, the difference between the market return for the treatment firm and that for the matched control firm is our measure of abnormal returns. Our final sample 
includes a broad cross-section of companies from around the world that are covered by the directive.

We first examine the on average (i.e., univariate) market reaction to these events. If equity investors perceive the benefits from this mandated nonfinancial reporting will exceed the costs, we predict a positive market reaction around events expected to increase the likelihood of the directive's passage. Alternatively, if equity investors perceive the benefits from this regulation to be less than the costs, then we predict a negative market reaction around such events. Benefits include potential increases in information relevant to assessing firm performance and improved management practices; costs include release of proprietary information, compliance costs, and adoption of management practices not beneficial to shareholders. We find an on average negative abnormal return surrounding adoption of this directive, robust across several methods and samples. We interpret this as consistent with investors anticipating net costs on average from the directive.

We then conduct our primary analyses, which exploit cross-sectional variation in this abnormal return. Specifically, we estimate a multivariate model including firm, industry, and country characteristics as determinants of the abnormal stock price reactions for the treatment firms, providing four principal insights. First, we document a more negative stock price reaction for firms having low disclosure levels of nonfinancial information prior to the directive. We interpret this as consistent with the directive increasing the likelihood of disclosure of worsethan-expected news, as well as anticipated proprietary or political costs for such firms. Related, we find a more negative stock price reaction for firms in industries exhibiting the highest levels of nonfinancial disclosure. We interpret this result as suggesting that firms belonging to such industries with clear nonfinancial disclosure leaders will face heightened costs of differentiation. 
Second, we document a more negative stock price reaction for firms with weak governance. We interpret this result as consistent with investors perceiving the benefit from any future disclosures to be lower for weak-governance firms, potentially reflecting anticipated lower quality nonfinancial disclosures for such firms. Third, we find a more negative stock price reaction for firms with weak environmental performance. We interpret this as consistent with investors anticipating that such firms-which are generating negative externalities-will be likely to incur future costs as they are forced to internalize those externalities. Finally, we find a more positive stock price reaction for firms having high levels of shareholder ownership from institutional asset owners such as pension funds and insurance companies. We interpret this result as consistent with greater demand for this nonfinancial information by this type of investor, as prior research documents such asset owners among the strongest proponents of mandatory nonfinancial disclosure (Serafeim 2015). Finally, we document on overall positive market reaction for those firms exhibiting strong nonfinancial performance and disclosure before the regulation, suggesting considerable heterogeneity in the market response to these events.

These cross-sectional findings are robust to a variety of analyses, including: (i) alternative matching algorithms, such as replacing the country-sector matching with a more restrictive country-industry matching; (ii) excluding firms domiciled in the US, the country having the largest percentage of our sample observations; (iii) including only EU firms; and (iv) including the percentage of shares held by socially responsible investment (SRI) funds. Finally, consistent with prior event studies on market-level regulatory changes, we conduct an analysis to identify confounding events that could bias our results; we fail to find such evidence.

This study contributes to our understanding of the effects and investor relevance of nonfinancial disclosures. Prior research provides evidence that voluntary nonfinancial disclosure 
has economic effects (Dhaliwal et al. 2011, 2012; Cheng et al. 2014) and that investors seek nonfinancial data (Eccles, Krzus and Serafeim 2011). Other research finds that regulations in particular countries, which mandated the disclosure of nonfinancial information, led to increases in the quantity and quality of nonfinancial information (Ioannou and Serafeim 2015). ${ }^{1}$ We build on these papers by providing evidence that the equity market perceived that mandating the provision of nonfinancial information would (on average) lead to net costs for affected firms; in particular, we find that the equity market perceived these net costs to be concentrated in firms with weaker nonfinancial disclosure and performance before the regulation. In contrast, for firms that have made investments to improve their performance on environmental, social and governance issues and to provide disclosures around them, investors expect net benefits. We conclude that investors expect an emphasis on nonfinancial issues to benefit some firms and to disadvantage other firms.

Section II provides the background and hypothesis development. Section III presents our research design. Section IV describes our sample selection and descriptive statistics. Section V presents our primary results, and Section VI our sensitivity analyses. Section VII concludes.

\section{BACKGROUND AND HYPOTHESIS DEVELOPMENT}

\section{Background}

In recent decades, there has been spectacular growth in the number of firms disclosing nonfinancial information. For example, over the past twenty years the number of companies issuing sustainability or CSR reports has increased from less than 50 to more than 6,000 (Serafeim 2014). Factors contributing to this increase in disclosure include pressure from

1 We are also related to papers examining how nonfinancial measures and performance relate to other aspects of the firm's information environment (e.g., earnings quality in Kim et al. 2012) or operating decisions (e.g., corporate tax avoidance in Hoi et al. 2013). 
stakeholder groups on companies to disclose information relating to the environmental and social impact from their operations, as well as the governance procedures that ensure that such considerations are taken into account (Delmas and Toffel 2008; Reid and Toffel 2009).

In addition, there has been increased investor interest in nonfinancial data (Eccles, Krzus, and Serafeim 2011). For example, heightened government regulation around environmental issues has been shown to contribute significantly to increased non-regulated disclosure of environmental liabilities (Barth, McNichols, and Wilson 1997). Similarly, investor and regulatory concerns around environmental issues are associated with increased narratives for environmental disclosures (Neu, Warsame, and Pedwell 1998). Prior research also documents a positive relation between environmental performance and environmental disclosure consistent with broader predictions of voluntary disclosure theory (Clarkson et al. 2008). The same line of research finds that firms with unfavorable prior year media coverage are more likely to make soft claims of environmental commitments, which are not readily verifiable, consistent with sociopolitical theories that stress the importance of organizational legitimacy (Clarkson et al. 2008).

The disclosure of nonfinancial information also has been shown to have economic effects. Prior research documents that firms with superior environmental, social, and governance (ESG) performance have better access to finance and lower capital constraints, in part due to the higher ESG disclosure (Cheng, Ioannou and Serafeim 2014). Related, other studies document that firms issuing sustainability reports exhibit a lower cost of capital (Dhaliwal et al. 2011; El Ghoul et al. 2011).

While most of the preceding research is built on firms' voluntary disclosure practices, more recently several mandatory nonfinancial disclosure regulations have emerged. Ioannou and Serafeim (2015) finds that firms in four countries (China, Denmark, Malaysia, and South Africa) 
not only increase disclosure, but also seek assurance of those disclosures and adopt reporting guidelines that increase comparability of disclosed information. Other research reveals that mandatory disclosure programs have forced companies to improve their operating performance relating to the environment (Delmas, Montes-Sancho, and Shimshack 2010) or food and water safety (Bennear and Olmstead, 2008; Jin and Leslie, 2003). However, no research examines investor perceptions of the expected costs and benefits to the announcement of regulations mandating such nonfinancial disclosures.

Prior research in accounting investigates market reactions to the announcement of mandated financial disclosure regulations. Much of this research focuses on equity market reactions to particular accounting standards in the US, such as fair value accounting required under Statement of Financial Accounting Standards (SFAS) 115 (Beatty et al. 1996; Cornett et al. 1996), and employee stock-based compensation under SFAS 123 (Dechow et al. 1996).

However, our setting relates more closely to other research examining the market reaction to regulation with broader implications, regarding either the regulation's effect on the nature of information being mandated, or the set of relevant firms affected by it. Two primary examples are the adoption of International Reporting Standards (IFRS) and passage of the Sarbanes-Oxley Act (SOX). Regarding IFRS, Armstong et al. (2010) examines the EU stock market reaction to events affecting the likelihood of IFRS adoption. The paper documents an (on average) significantly positive market reaction to these collective events, as well as crosssectional variation revealing a more positive reaction for firms having lower quality pre-adoption information and higher pre-adoption information asymmetry (suggesting anticipated improvements in information quality under IFRS), and a more negative reaction for firms domiciled in code law countries (suggesting anticipated concerns over enforcement of IFRS in 
those countries). Related, Joos and Leung (2013) examines the stock price reaction of US firms to IFRS adoption events. The paper documents a marginally positive overall US market reaction, as well as more positive abnormal returns for firms operating in industries where IFRS is already widely adopted by non-US peer firms, for larger and more liquid firms, and for firms with high foreign institutional ownership. Joos and Leung (2013) interprets these results as consistent with investors reacting more positively to IFRS adoption when it is expected to result in convergence benefits.

Our paper is also related to several studies examining the market reaction to events affecting passage of SOX. Jain and Rezaee (2006) and Li et al. (2008) find significantly positive abnormal stock returns associated with legislative events increasing the likelihood of SOX's passage, concluding that investors perceived SOX to be overall net beneficial. In contrast, Zhang (2007) documents negative cumulative abnormal returns for US firms and foreign firms complying with SOX around similar events, concluding SOX imposes net costs on complying firms.

Collectively, these studies infer investor perceptions of the net costs or benefits associated with the regulation by examining the equity market reaction to events leading to its adoption. Accordingly, we follow this research, and use the equity market reaction to events affecting passage of mandatory nonfinancial disclosures in the EU to assess the expected net costs or benefits associated with this regulation, as well as predictable cross-sectional variation. Finally, we note that Leuz (2007), in evaluating the studies examining the market reaction to events affecting passage of SOX, argues it is difficult to attribute the event date market reactions solely or principally as investor response to passage of the studied regulation. This is because the SOX regulation was imposed on virtually all publicly-traded US firms, making it difficult to 
identify a natural control group to remove market-wide effects that are unrelated to the regulation. Similar concerns can affect studies relating to the passage of IFRS, due to its widespread impact on publicly-traded firms in the adopting markets. In contrast, the directive mandating nonfinancial disclosure in our setting applies to a subset of EU-listed companies; as discussed later, this affords more flexibility in identifying a suitable control group of comparable but unaffected firms.

\section{Hypothesis Development}

\section{Univariate Predictions}

The mandated disclosure of nonfinancial information could lead to both costs and benefits from an equity investor standpoint. Benefits include the increased availability of information relevant both for valuation and monitoring purposes. Specifically, better information can improve either the prediction of firms' future performance (i.e., expected cash flows) and/or lead to clearer expectations regarding the inherent risks facing the firms. This can lead to a reduced costs of capital through lower information risk (Easley and O'Hara 2004), and thus a positive stock price reaction. In addition, better information can improve the ability of investors to monitor firms on dimensions potentially having cash flow implications (e.g., environmental performance); this, too, would generate a positive stock price reaction. Another mechanism through which investors could benefit is if mandatory disclosure of nonfinancial information leads firms to improve their operational efficiency, such as through reduced energy consumption and waste generation, improved product quality and customer service, or better 
employee recruitment, retention and development. ${ }^{2}$ Collectively, these changes would lead to a positive market reaction to the increased likelihood of the regulation's passage.

However, investors will react negatively to the regulation if (on average) the anticipated costs outweigh the expected benefits. One source of costs includes those related to the direct preparation, dissemination, and assurance of the new information. However, an EU impact assessment study indicates that "the cost of a full mandatory reporting obligation could therefore be roughly estimated in a range varying between $€ 33,000$ and $€ 604,000$ per year per company," with the actual number being a function of the company's size. ${ }^{3}$ The seemingly limited materiality of these costs, relative to the scale of the affected firms, suggests they are unlikely ex ante to be a primary driver of any observed negative market reaction to this regulation. Another potential cost relates to proprietary costs of disclosure. Specifically, if firms are forced to disclose information expected to be harmful to their competitiveness, this too would lead to a negative market reaction. This is possible, if the mandated disclosures convey competitive advantages to other firms, allowing them to (in expectation) emulate such activities. A third potential source of costs is political costs. To the extent investors anticipate that disclosure of this information allows governments, regulators or NGOs to pressure firms to invest their capital on projects perceived as negative net present values to shareholders, investor reaction around the announcement of the regulation will be negative.

In summary, the disclosure regulation is likely to generate both costs and benefits. As the net effect is difficult to predict ex ante, we do not make a directional univariate prediction.

2 Indeed, the recent regulation suggests that "a strategic approach to CSR is increasingly important for competitiveness, as it can bring benefits in terms of risk management, cost savings, access to capital, customer relationships, human resource management and innovation capacity." See http://eur-lex.europa.eu/legalcontent/EN/ALL/?uri=CELEX:52013SC0127.

3 See http://eur-lex.europa.eu/legal-content/EN/ALL/?uri=CELEX:52013SC0127. 


\section{Cross-Sectional Predictions}

However, we expect cross-sectional variation in how the regulation is perceived to be net beneficial or costly. Accordingly, we examine variables that could affect the relative magnitude of costs and benefits. Our main experimental variables focus on firms' level of disclosure and performance on nonfinancial issues. We predict that firms disclosing low levels of nonfinancial disclosure will have a more positive stock price reaction, if investors expect that they will receive value relevant information from these firms in the future. However, if investors expect that such firms will be forced to (i) disclose news more negative than expected (such as that relating to their environmental impact, employee relations, product safety, (ii) to reveal proprietary information, or (iii) to incur political costs as a result of increased disclosure, then we expect a more negative stock price reaction. Similarly, we predict a more positive stock price reaction for firms with poor nonfinancial performance if investors expect that these firms in doing so will improve their nonfinancial—and thus future financial—performance. Alternatively, if investors expect these firms will be forced to improve their performance on nonfinancial issues to the detriment of financial performance, then we predict a more negative stock price reaction.

We also hypothesize that the investor reaction to passage of mandatory nonfinancial disclosures will be a function of several other firm characteristics. First, we predict that firms with higher institutional ownership will have more positive stock price reactions, reflecting higher demand for information from such investors. Prior research suggests that institutional investors, particularly asset owners such as large pension funds and investment arms of insurance companies, have been a driving force behind increases in these disclosures (Serafeim 2015). Second, we predict that firms with large unrecognized assets (such as brands, human capital, intellectual capital, or social capital) will exhibit more positive stock price reactions as the 
nonfinancial disclosures will be informative about assessing the value of these assets. Third, we predict that smaller firms to have more negative stock price reactions due to proportionately higher costs of compliance for these firms as the regulation could be proportionately more costly.

We also expect several key industry characteristics to explain cross-sectional variation in investor reaction to this mandated nonfinancial disclosure. First, we predict that industries with firms having high levels of nonfinancial disclosure will exhibit more negative stock price reactions, as firms in such industries will be forced to converge to the leading company in terms of disclosure, leading to greater costs to achieve these higher levels of disclosure. Second, we predict that industries with higher rents will face higher political costs, and therefore a more negative stock price reaction as they will face pressure to share profits with other stakeholders. Third, we predict that industries with a large environmental impact will have more negative stock price reactions, as these firms will face incremental pressure to limit their environmental impact thereby incurring costs.

Finally, we expect several country characteristics to explain cross-sectional variation in investor reaction. To the extent that investors perceive benefits from the future disclosures, we predict more positive stock price reactions in countries where institutions ensure the disclosure of high quality information. Second, we predict that firms in countries with stronger regulatory regimes will exhibit more negative stock price reactions, as these firms will be more likely to face political costs. In addition, given that a few countries had already adopted disclosure regulations for nonfinancial information (such as China, Denmark, France, India, Malaysia, and South Africa, we expect investor reactions to be smaller in those countries (i.e., less negative in the case of net costs, or less positive in the case of net benefits). 


\section{RESEARCH DESIGN}

\section{Dependent Variable}

Consistent with prior research examining the market reaction to events affecting the likelihood of passage for mandatory nonfinancial disclosures, our dependent variable is $C A R_{i}$, the cumulative abnormal return for firm $i$ to events identified as affecting the likelihood of passage for the directive mandated increased nonfinancial disclosures in the EU.

Several research design choices relating to our dependent variable warrant discussion. First, consistent with prior research, our return measure is accumulated over days $(-2,+2)$, where day 0 is the event date. Use of a five-day span ensures that we capture any leakage regarding the regulation prior to its official release date, as well as ensuring sufficient time for the equity markets to impound the anticipated effects of the events into firms' stock prices. Because our sample spans equity markets from different countries, this mitigates concerns of differences in overall levels of market efficiency. We note that results are robust to alternatively using a 3-day $(-1,+1)$ return.

Second, following prior research (e.g., Armstrong et al. 2010), our analyses focus on the aggregation of market reactions across the identified events. That is, we draw our inferences from assessment of the market reactions to all events aggregated together, as opposed to assessing each event individually, because the passage of this directive resulted from a process that evolved over several years. Restated, we view these events as collectively affecting the likelihood of regulation's passage, with the equity market's reaction to any particular event and its effect on passage of the directive being conditional on the collective responses from previous events. In addition, aggregation across the events reduces noise that may occur in any particular 
event; for example, due to the release of other non-regulation information not fully removed from the observed market return.

Third, a critical research design choice in event studies-particularly those examining regulatory events affecting a large population of firms-is the identification of a benchmark return to appropriately remove any non-regulatory news coinciding on the examined event dates to derive an "abnormal" stock return. To derive the benchmark return, we assign each treatment firm to a corresponding control firm, matched on the basis of country, sector, market capitalization, and price-to-book ratio. Matching on country of domicile eliminates any market reaction coinciding on our examined event dates that is attributable to country-specific news unrelated to our examined regulation. Similarly, matching on sector eliminates any sectorspecific economic news reflected in the market reaction on our event dates. Finally, matching on market capitalization and price-to-book controls for general effects attributable to the information environment, risk, or growth that coincides with firms having a similar size and price-to-book ratio. Thus, for each event, we calculate the difference between the observed 5day stock return for treatment firm $i$, after removing the corresponding 5-day return for the control firm $j$. For each firm $i$, we then aggregate these differences across the three identified sample events, to derive our firm-specific $C A R .^{4}$

\section{Cross-Sectional Analyses}

To assess cross-sectional variation in the market response to our identified events, we estimate the following regression:

$$
C A R_{i}=\alpha_{1}+\beta_{1} E S G \_D i s c l \_S c o r e_{i}
$$

4 We note that our results are unchanged to additionally matching on the variable ESG_Discl_Score, which measures the quantity of the firm's ESG disclosures. This matching procedure helps to address potential selfselection of firms into the amounts of non-financial disclosures being provided. 


$$
\begin{aligned}
& +\beta_{2} \text { Gov_Score }_{i}+\beta_{3} \text { Social_Score }_{i}+\beta_{4} \text { Envir_Score }_{i} \\
& +\beta_{5} \text { AssetMgr }_{i}+\beta_{6} \text { AssetOwner }_{i} \\
& +\beta_{7} M T B \_T o p Q_{i}+\beta_{8} M C a p \_B o t Q_{i} \\
& +\beta_{9} \text { Ind_MaxESGDiscl }{ }_{m}+\beta_{10} \text { Ind_AvgROA }_{m}+\beta_{11} \text { EnvWeight }_{m} \\
& +\beta_{12} \text { CommonLaw }_{k}+\beta_{13} \operatorname{Reg}_{\text {Rual }_{k}}+\beta_{14} \text { NationalReg }_{k}+\varepsilon_{i}
\end{aligned}
$$

The dependent variable is $C A R_{i}$, the cumulative abnormal return for firm $i$ aggregated across the three identified events affecting passage of the directive.

The experimental variables are defined as:

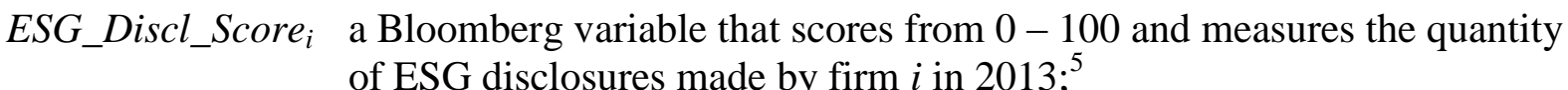

Gov_Score $_{i}$

a MSCI variable that scores from $0-10$ and measures the quality of firm $i$ 's governance processes and structure in $2013 ;^{6}$

5 Bloomberg calculates an ESG (environmental, social, and governance) Disclosure score to quantify a company's transparency in reporting ESG information. Environmental data relate to emissions, water, waste, energy and operational policies around environmental impact. Examples include the level of scope 1, 2 and 3 carbon emissions, the amount of waste discarded, percentage of water usage from recycled sources, the amount of electricity used, environmental fines, and the total amount of materials recycled. Social data relate primarily to employees, products and impact on communities. Examples include employee turnover, percentage of women in workforce, lost time incident rate, community spending, number of customer complaints, and number of suppliers audited based on social criteria. Governance data relate to board structure and function, firm's political involvement, and executive compensation. The data are collected from any available corporate disclosure such as annual reports, sustainability reports, and other public corporate presentations. This score is based on 100 out of 219 raw data points that Bloomberg collects, and is weighted to emphasize the most commonly disclosed data fields. The weighted disclosure score is normalized to range from zero (for companies that do not disclose any ESG data) to 100 for those companies that disclose every data point collected. Bloomberg accounts for industryspecific disclosures by normalizing the final score based only on a selected set of fields applicable to the industry type. For example, "Total Power Generated" is counted into the disclosure score of utility companies only. Past research has shown that these disclosure scores, among all ESG related data fields, are the ones that attract the most attention by investors (Eccles, Krzus and Serafeim 2011).

6 MSCI (Morgan Stanley Capital International) ESG Research provides environmental, social and governance ratings, screening and compliance tools to investors wanting to integrate nonfinancial factors into their investment processes. Analysts first determine the key nonfinancial issues affecting each industry that have the highest potential material impact on a company's financial performance, and assign a weight (indicating relative importance) to each key issue. Using a combination of company-disclosed and third-party sources, analysts score each company on each key issue on a scale from 0 (worst) to 10 (best). This score evaluates the companies' relative risk exposure and performance as compared to best practice in the industry. On an asneeded basis, analysts contact company management following preliminary research to request specific data that is missing from the analysis. The weighted average of the key issue scores are aggregated to provide each company with an overall ESG performance score, as well as three disaggregated performance scores (one each for environmental, social, and governance). Company ratings are generally updated on an annual cycle when all companies in its industry are reviewed; however, individual reviews and ratings changes can occur when a 
Social_Score $_{i} \quad$ a MSCI variable that scores from $0-10$ and measures the performance of firm $i$ in relation to human capital, health and safety, products and services, and supply chain issues in 2013;

Environ_Score $_{i} \quad$ a MSCI variable that scores from $0-10$ and measures the performance of firm $i$ in relation to energy and climate change, natural resource consumption and waste management issues in 2013;

AssetMgr $_{i} \quad$ the percentage of outstanding shares of firm $i$ held by asset managers defined as investment advisors, mutual funds and hedge funds (calculated using 2013 Bloomberg data);

AssetOwner $_{i} \quad$ the percentage of outstanding shares of firm $i$ held by asset owners defined as pension funds, insurance companies and bank trusts (calculated using 2013 Bloomberg data);

$M T B_{-} T_{T o p} Q_{i} \quad$ an indicator variable equaling one if firm $i$ is in the top quartile of marketto-book ratio, and zero otherwise;

MCap_Bot $Q_{i} \quad$ an indicator variable equaling one if firm $i$ is in the bottom quartile of market capitalization, and zero otherwise;

Ind_MaxESGDiscl $l_{m}$ the maximum level of ESG disclosure in 2013 across all firms in firm $i$ 's industry $m$;

Ind_AvgROA $A_{m} \quad$ the average level of ROA in 2013 across all firms in firm $i$ 's industry $m$;

EnvWeight $_{m} \quad$ an MSCI variable measured in 2013 that ranges from $0-100 \%$ and scores an industry $m$ by taking into account both its contribution, relative to all others, to the negative impact on the environment; and the timeline within which we expect that financial risk for companies in the industry would be expected to materialize;

CommonLaw $\quad$ an indicator variable equaling 1 if country $k$ (the country of firm $i$ 's domicile) is a common law country, and zero otherwise;

RegQual $_{k} \quad$ country $k$ 's 2013 World Bank rating of its regulatory quality, which captures perceptions of the ability of the government to formulate and implement sound policies and regulations that permit and promote private sector development; and

NationalReg $g_{k} \quad$ an indicator variable equaling 1 if country $k$ (the country of firm $i$ 's domicile) already mandates similar nonfinancial disclosures in 2013 as those being mandated in the examined directive, and zero otherwise.

company is involved in an extraordinary "ESG Event" with substantial negative social or environmental impact. MSCI ESG coverage has increased from 250 firms in 1999 to over 6,000 firms in 2014. 
We make the following cross-sectional predictions. Regarding firm-level variables, if investors expect that firms with higher levels of ESG disclosure and performance prior to the mandated regulation will incur incrementally higher net costs (net benefits), then we predict the coefficients on ESG_Discl_Score, Govern_Score,Soc_Score, and Environ_Score to be negative (positive). If institutional investors demand more nonfinancial information relative to that mandated by the regulation, we predict the coefficients on Asset_Mgr and Asset_Owner to be positive. If the nonfinancial disclosures are expected to provide information particularly relevant to those firms having significant unrecognized intangible assets, we predict the coefficient on $M T B \_T o p Q$ to be positive. If smaller firms are expected to incur relatively higher proportional costs of implementation due to the mandated disclosure regulation, we predict the coefficient on $M C A P \_B o t Q$ to be negative. ${ }^{7}$

Regarding industry-level variables, if the costs of converging in terms of disclosure are expected to be highest in industries having firms with high pre-regulation nonfinancial disclosures, the predicted coefficient on Ind_Max_ESGDiscl is negative. If industries exhibiting strong economic performance are more likely to face increased political costs to force the sharing of profits with other (nonequity) stakeholders, we predict the coefficient on Ind_Avg_ROA to be negative. Finally, if the mandated nonfinancial disclosures are expected to force industries having large environmental impacts to incur incrementally higher costs to limit this impact, the predicted coefficient on EnvWeight also is negative.

7 We note that our predictions relate to the absolute level of a firm's performance or disclosure, not its level relative to its industry. We follow this process, because industry benchmarking could add measurement error and noise in our estimates as it would not be consistent with investor expectations. Consider the following example: a carbon tax regulation would affect a coal company with the best environmental performance (firm A) more than it would affect a technology firm with the worst environmental performance (firm B), since even the most environmentally-conscious coal company has higher carbon emissions than the least-environmentally conscious technology firm. However, industry-adjusting environmental performance would likely create the impression that firm A is less affected by the regulation than firm B, which is incorrect. 
Regarding country-level variables, to the extent that investors perceive benefits from the future disclosures to be more concentrated in firms domiciled in countries with a common law tradition, we predict a positive coefficient on CommonLaw. Further, we predict a negative coefficient on RegQual, as these firms will be more likely to face political costs. Finally, we expect investor reactions to be smaller in countries that have already adopted disclosure regulations for nonfinancial information, as the expected net costs are likely lower; this leads to a positive predicted coefficient for NationalReg.

\section{SAMPLE SELECTION AND EVENTS}

\section{Sample Selection}

Table 1 presents our sample selection. Our initial sample consists of Bloomberg's 2014 population of 15,133 firms with ESG coverage. Bloomberg has the widest coverage among data providers in terms of ESG disclosure, and its ESG analysts cover the largest companies in the world (Ioannou and Serafeim 2015). We exclude firms missing any of the event returns; we also exclude firms domiciled in South Africa, which all focus on commodities, due to likely confounds in inferences. ${ }^{8}$ This yields a sample 12,162 available firms.

We separate this latter group into those affected versus unaffected by the directive. Firms affected by the directive are identified using the Proposal for the Directive (Proposal) on nonfinancial reporting, obtained from the EUR-Lex database. The Proposal specifies that the new rules apply only to companies (both listed as well as other public-interest entities, such as banks and insurance companies) having over 500 employees, operating in any of the $28 \mathrm{EU}$ member

8 Specifically, the available publicly-traded South African firms in our set focus on natural resource extraction, particularly gold. Gold prices exhibit high volatility on our event dates (with average stock returns of almost $15 \%$ for these firms), leading to the likely confound in inferences for this subgroup. 
countries, and having either a balance sheet total of $€ 20$ million or revenues of $€ 40$ million. ${ }^{9}$ The Proposal further stipulates that companies listed on an EU stock exchange and meeting the size threshold are affected by the new ruling even if they are registered outside of the EU. Using Worldscope data (supplemented with hand-collected data on employee count), we identify 2,417 firms falling under the scope of the Directive; this constitutes our treatment sample.

The remaining 9,745 firms $(12,162$ less 2,417$)$ defines the sample of potential control firms. To match treatment with control firms, we employ a matching algorithm as follows. We identify treatment and control firm pairs headquartered in the same country and operating in the same Global Industry Classification Standard (GICS) sector, and then find the closest match in terms of total market capitalization and price-to-book ratio. Our matching process requires exact matching on country and sector membership and then minimizes the distance between the treatment and control firms in terms of size and price-to-book ratio. We first delete 364 treatment firms due to inability to obtain a matched control firm in the same country-sector pair, leaving a final sample of 2,053 pairs; this is the group used for our univariate analyses. We then impose the additional data requirements for our cross-sectional tests, leading to a matched sample of 1,249 treatment/control firm pairs. Missing data on the ESG performance pillars is the primary cause for the reduced sample.

Table 2 presents the distribution of our treatment observations. Panel A presents the frequency by country, and Panel B presents that by sector. The panels provide two primary insights. First, the country and sector distribution of the sample firms prior to matching in Column (1) is quite similar to that after matching for the univariate analyses in Column (2). Second, while the sector distribution for the sample firms having necessary data for the cross-

9 Proposal for a Directive of the European Parliament and of the Council amending Council Directives 78/660/EEC and 83/349/EEC as regards disclosure of non-financial and diversity information by certain large companies and groups: http://eur-lex.europa.eu/legal-content/EN/TXT/?uri=CELEX:52013PC0207. 
sectional analyses in Column (3) is similar to the other two samples, the country distribution for the cross-sectional sample now attains a larger percentage weighting in the US. This reflects the greater availability of data for US firms; we explore the robustness of our results to excluding the US observations in a later sensitivity analysis. Focusing on the sample for the cross-sectional analyses in Column (3), the primary countries represented are Japan (5.5\%), United Kingdom (19.4\%) and the US (48.2\%), and the primary sectors represented are consumer discretionary (19.5\%), financials $(18.5 \%)$, and industrials (17.9\%).

\section{Sample Events}

We identify three events during 2011-2014 that we assess as having a major effect on the likelihood that nonfinancial reporting would be mandated in the EU. To identify potential events, we (i) examine press releases and public document listings by the European Parliament, the European Commission, and the European Financial Reporting Advisory Group; and (ii) search Dow Jones News Retrieval using the terms "nonfinancial reporting", "social and environmental information", "EU nonfinancial legislation" and "EU mandatory nonfinancial disclosure." This search provides an initial listing of 20 events. ${ }^{10}$ We verified each event's timing, content, and likely directional effect on the likelihood of mandating nonfinancial disclosure in the EU. We eliminated events confirming earlier events, those relating to broader environmental, social and governance (ESG) issues, and those relating to nonfinancial disclosure. ${ }^{11}$ This process leads to three events that we assess as impacting the likelihood of nonfinancial reporting being mandated in the EU.

10 The listing of these twenty events is available upon request.

11 For example, the European Commission released a report on October 15, 2011 entitled "A renewed EU Strategy for Corporate Social Responsibility." In addition to specifying the Commission's commitment to propose legislation on the mandated disclosure of ESG information by EU firms, the report also discusses over 40 other 
The first event is April 16, 2013, when the EU Commission presented the Proposal for the Directive to amend existing accounting legislature with the intent of improving the disclosure of ESG matters by certain large companies. Under the proposal, large companies (defined as those having 500 or more employees, and either total assets of $€ 20$ million or sales revenue of $€ 40$ million) would be required to disclose relevant material ESG information in their annual reports. While mandatory nonfinancial reporting had been under discussion in the EU prior to this event date, this date marks the first clear commitment by the EU to require companies to disclose this information. ${ }^{12}$ We also note that while this event consists of the presentation (versus passage) of the Proposal, it occurs after considerable efforts to understand the need for the legislation, solicit stakeholders' feedback regarding the legislation, and outline the framework and legal elements of the legislation. Further, the EU Commission rarely presents a Proposal unless there is clear support for its adoption. Our second event date is February 26, 2014, when the European Parliament and the European Council reached an agreement on the Proposal. Our third event date is April 15, 2014, when the European Commission adopted the Proposal. ${ }^{13}$ Both latter events relate to the Proposal's adoption. We view all three sample events as increasing the likelihood of the EU adopting mandatory nonfinancial reporting requirements.

commitments from the Commission relating to improving corporate ESG practices and established guidelines. As this event relates to both reporting and non-reporting ESG issues, it is eliminated from our sample events.

12 As stated in the Proposal for the Directive, the proposal reflects the findings of over two years' worth of consultations, dialogues and impact assessments that the Commission maintained with interested parties, including preparers, users and non-governmental organizations. A number of dialogues lead to this proposal, including: (1) in 2011 and 2012, two public consultations on the disclosure of non-financial information by EU companies, with an overall majority of stakeholders supporting the need to improve the current legislative framework; (2) in 2011 and 2012, five Expert Group meetings with stakeholders and Member States' representatives took place, where details concerning the legislative proposal were discussed; and (3) in 2010 and 2011, two impact assessments were undertaken by the Commission to identify issues concerning the inadequate transparency of nonfinancial information.

13 We note that the Proposal was officially passed into law on September 29, 2014, when it was adopted by the EU Member States in the European Council. We exclude this event, as it is a formality that simply confirms the vote to adopt the Proposal on April 15, 2014. As indicated in the European Commission's press release of April 15, 2014 states: "Following today's adoption by the European Parliament, the Council is expected to formally adopt the proposal in the coming weeks". 
In addition, we searched for events that would decrease the likelihood of the EU adopting mandatory nonfinancial reporting requirements to allow investigation of events with opposite stock price reactions to the above; however, we were unable to find such events.

\section{Confounding News}

Common to event studies, we examine whether particular non-directive related news is issued systematically across our three identified events, to mitigate concerns of confounds regarding observed market reactions. We search the US and European editions of the Wall Street Journal, including "World Markets" articles, as well as the US and European editions of Reuters, Bloomberg and the European edition of the Financial Times, for news unrelated to mandatory EU nonfinancial reporting during our event windows. We search for news on the day preceding, day of, and day after the event. We filter our search to include only headline listings, headlineonly content and page-one stories. For our first event date (April 16, 2013), we note that the terrorist attacks at the Boston Marathon on April 15, 2013 likely negatively affected the returns of (particularly) US firms. We further note that on April 15, 2013 gold prices fell by over 9\% to a two-year low, which we expect to negatively impact the returns of firms in the mining industry. For our third event date (April 16, 2014), we note that banks operating in the EU are likely negatively affected by the adoption of several landmark banking reforms on April 16, $2014 .^{14}$

For these global news events that could potentially confound the attribution of our events to the observed market reaction, we pay particular attention to the abnormal event returns and the

\footnotetext{
14 In addition, a bias could arise if (i) around the events firms release their earnings numbers and (ii) earnings surprises are systematically higher or lower for treatment firms compared to control firms. Accordingly, we also calculate earnings surprise $\left(E \_S U R P\right)$ for each firm and include it as an additional control variable in our crosssectional model. E_SURP is measured as the difference between the actual and last consensus forecast divided by absolute actual earnings in 2013 and 2014, and averaged across the two years. The coefficient on $E \_S U R P$ is insignificant; further, all other results are unchanged.
} 
appropriateness of the matched control firms. For the first event date with potentially confounding news of the Boston Marathon bombing, we note that the average abnormal return for the 605 US treatment firms (that is, the difference between the treatment and control firm return) is $0.31 \%$. Similarly, the average abnormal return for European banks on the third event date (with the potentially confounding news of the EU bank reform) is $-0.14 \%$. Thus, the matching appears to mitigate any extreme non-regulatory market effects attributable to either the bombing or the banking reform.

Finally, we note a potential confound with the first event that leads us to exclude all firms from South Africa from our primary sample. We observe starkly declining gold prices around our first event, evidenced in the 41 treatment firms belonging to the metals and mining industry (GICS 151040) having large negative returns (-13\%). We investigate related treatment firms with absolute abnormal returns above $1 \%$ on this event date to confirm the appropriateness of the control firms. Of note, the seven South African precious metal mining and exploration companies are initially matched with steel production firms, which share the same GICS 151040. Due to the lack of suitable control firms to eliminate effects due to the dramatic change in gold price (versus the regulation effects we wish to capture), we exclude the South African firms from our analyses.

\section{EMPIRICAL RESULTS}

\section{Univariate Analyses}

We first examine the overall market reaction to the three events to assess whether investors worldwide perceive mandated nonfinancial reporting to be, on average, net beneficial or costly. Table 3 presents the cumulative five-day raw stock return, centered on event dates, 
and aggregated across our three events. Panel A presents the mean raw event returns, size and growth characteristics of our treatment and control samples for three comparisons: (i) before matching in Columns (1) - (2); (ii) after matching but before imposing cross-sectional data requirements in Columns (3) - (5); and (iii) after matching and imposing cross-sectional data requirements in Columns (6) - (8). We first document that the average market reaction is negative and similar in magnitude prior to matching: -0.0256 for the treatment firms in Column (1) $(N=2,471)$, and -0.0260 for the control firms in Column (2) $(N=9,745)$. However, once we impose our matching, we find that the treatment firms exhibit significantly more negative market reactions to the cumulated three events. Specifically, using the matched firms for the univariate analyses ( $N=2,053$ firm pairs), we find a reaction of -0.0250 for the treatment firms in Column (3), and -0.0171 for the control firms in Column (4); the difference of -0.0079 (i.e., $0.79 \%$ ) in Column $(5)$ is significantly negative $(t$-stat $=2.74)$. Similar results obtain using the matched firms for the cross-sectional analyses ( $N=1,249$ firm pairs), with the difference of -0.0071 $(0.71 \%)$ in Column (8) again significantly negative $(t$-stat $=2.60)$.

We note that our treatment firms appear to have larger market capitalizations relative to the control firms. For example, the average market capitalization (end of 2013) before matching is $\$ 7,782$ ( $\$ 1,538$ ) million for the treatment (control) firms. However, this difference is considerably attenuated as we move across the three sample groupings: for example, in the crossectional sample, the average market capitalization is $\$ 12,556(\$ 9,279)$ million for the treatment (control) firms. In addition, the matching appears to eliminate differences in market-to-book 
ratios across the treatment and control samples: the difference is insignificant once we impose the matching. This provides some validation of the control firms as appropriate benchmarks. ${ }^{15}$

Panel B then presents results of regressing the cumulative 5-day raw event returns on treatment versus control firms, after directly controlling for market capitalization and the marketto-book ratio. Thus, to the extent the matching does not completely eliminate market effects attributable to the size or market-to-book, this analysis explicitly controls for such effects. Of note, we find an on average negative market reaction of $-1.01 \%$ (coefficient for Treatment $=-$ 0.0101, $t$-stat $=2.68$ ) for the treatment firms under the matched sample before imposing the cross-sectional data requirements. Similarly, we find a significant negative market reaction of $1.20 \%($ Treatment $=-0.0120, t$-stat $=2.72)$ for the treatment firms under the matched sample after imposing the cross-sectional data requirements.

Overall, these results are consistent with the stock market perceiving that adoption of mandatory nonfinancial disclosures under the proposed regulation would lead to net costs on average. We now turn to the cross-sectional analyses to better understand the drivers of these expected net costs.

\section{Cross-Sectional Analyses}

Table 4 presents descriptive statistics (Panel A) and Pearson correlations (Panel B) for the variables used in our cross-sectional analyses of Equation (1), which is estimated using

15 To further mitigate the effect of size on our estimates we include it as a control in our multivariate regressions in Panel B. Moreover, in additional analysis reported later in the paper we impose stricter filters that force size differences to be minimized further. 
observations for which data are available for all three events $(N=1,249$ for country-sector matching). All variables are measured as of 2013 calendar year-end. ${ }^{16}$

Focusing on Panel A, on average the sample treatment firms have nonfinancial disclosure scores of 30.187 (ESG_Discl_Score). As previously discussed, ESG_Discl_Score ranges from 0 - 100 and measures the quantity of ESG disclosures a firm makes. Prior research reveals that ESG disclosure has increased over time (Ioannou and Serafeim 2015), that firms with scores above 10.5 have above average levels of ESG disclosure in the total ESG Bloomberg universe as of 2013, and that firms with scores above 20.9 have above average levels of ESG disclosure among ESG-disclosers in the total ESG Bloomberg universe as of 2013. The panel also reveals average governance performance of 6.429 out of 10 (Govern_Score), social performance of 4.627 out of 10 (Soc_Score), and environmental performance of 5.473 out of 10 (Environ_Score). The MSCI scores range from $0-10$; in the total MSCI sample, firms with scores above 4.7 are considered to have above average levels of ESG performance as of 2013. The average firm's shares outstanding are mostly owned by asset managers (Asset_Mgr= 75.979), such as banks, hedge funds, mutual funds and investment advisors, while less than $4 \%$ are held by asset owners (Asset_Owner $=3.884$ ), such as pension funds and insurance companies. The industry leaders of nonfinancial disclosure have an average score of 56.885 out of a possible 100 (Ind_Max_ESGDiscl), as compared to the average nonfinancial disclosure score of 30.187 (ESG_Discl_Score). The industry return on assets is 5.069\% (Ind_Avg_ROA). Finally, $73 \%$ of sample firms are domiciled in common law countries $($ CommonLaw mean $=$ 0.728), $6 \%$ operate in countries having existing nonfinancial disclosure regulation in place

16 Our first event is before the 2013 calendar year-end while the latter two events are after. Measuring our variables in 2012 does not change our results but it restricts our sample because of a larger number of missing MSCI and Bloomberg data. Over time, both data providers have expanded their coverage. 
(National Reg $=0.055)$, and the average World Bank Regulatory Quality score (RegQual) is 1.413 out of 4 .

In Panel $\mathrm{B}$, the correlations reveal (consistent with expectations) that $C A R$ is significantly positively correlated with Govern_Score,Asset_Mgr,Asset_Owner, and MTB_TopQ. As expected, $C A R$ also is negatively correlated with $I n d \_M a x \_E S G \_D i s c l$ and RegQual. The correlations between $C A R$ the remaining variables are insignificant. ${ }^{17}$

Table 5 presents the cross-sectional results based on Equation (1); standard errors are clustered by country. Focusing on the firm-level experimental variables, we find a significantly positive coefficient on ESG_Discl_Score $(0.00030, t$-stat $=2.53)$, and a significantly positive coefficient on Govern_Score $(0.00311, t$-stat $=2.71)$. These are consistent with the equity market perceiving that firms having high ESG disclosure and stronger governance performance will be able to institute the regulation more efficiently and cost-effectively. Economically, a one-standard deviation increase in ESG_Discl_Score (Govern_Score) is associated with an increased market reaction of $0.49 \%(0.84 \%)$. We also find a significantly positive coefficient on AssetOwner $(0.00104, t$-stat $=2.70)$, consistent with investors perceiving that firms with higher institutional ownership have higher demand for nonfinancial information. A one-standard deviation increase in AssetOwner is associated with an increased abnormal return of $0.64 \%$. Finally, we find a marginally significantly positive coefficient on MTB_TopQ $(0.00925, t$-stat $=$ 1.61), consistent with investors expecting higher net benefits for firms with more intangible assets. The coefficients on the remaining firm-level variables are insignificant.

Turning to the industry- and country-level variables, we find a significantly negative coefficient on Ind_Max_ESGDiscl $(-0.00090, t$-stat $=2.60)$, consistent with investors expecting

17 While the panel reveals several larger correlations between the experimental variables (e.g., 0.548 correlation between CommonLaw and Asset_Mgr), these do not appear to affect our regression results: for example, VIFs for Table 5 are all less than 1.82 . 
higher net costs for firms operating in industries having "leaders" with high nonfinancial disclosures. Economically, a one-standard deviation increase in Ind_Max_ESGDiscl is associated with a decreased market return of $-0.79 \%$. We also find a significantly negative coefficient on RegQual $(-0.03484, t$-stat $=2.42)$. This suggests equity market participants reacted more negatively to mandated nonfinancial reporting for firms operating in countries with stronger regulatory regimes, consistent with investors in these firms expecting relatively higher political costs resulting from the mandate. The corresponding one-standard deviation effect of RegQual is a more negative return of $0.98 \%$. The coefficients on the remaining industry- and country-level variables are insignificant.

Finally, because our above analyses appear to suggest an overall negative reaction to the passage of these mandated nonfinancial disclosures, we estimate a regression to assess the reaction for the strongest sample firms. Following Armstrong et al. (2010, p. 54), we redefine all variables from Equation (1) as indicator variables equaling one when the firm exhibits the "lower quality" condition. As an example for the firm-level variables, we define an indicator variable to equal one when the firm has below median environmental pillar score (and thus weaker environmental reporting); as an example for the country-level variables, we define an indicator to equal one when the firm is listed in a code law country (and thus has weaker overall enforcement). All control variables are similarly defined, and thus capture the effects for those firms in the weakest reporting conditions. Critically, this provides a particular interpretation of the intercept: it now captures the average market response to our sample events for the strongest reporting firms, i.e., those firms in common law countries, having national nonfinancial disclosure regulations, with environmental, social, and governance reporting that is above median, etc. Untabulated results reveal that the intercept now equals to $0.0388(t$-stat $=1.69)$; 
this suggests that the average reaction for the very best firms is $3.88 \%{ }^{18}$ This provides an upper bound, and critically suggests that high quality firms exhibit a positive reaction to the mandated nonfinancial regulation.

Overall, the results from the cross-sectional analyses suggest that investors expect higher net costs from the mandated nonfinancial disclosures for firms with lower ESG performance, weaker governance, lower ownership by asset managers, in industries with firms having high nonfinancial disclosure, and in countries with high implementation and formation of regulation.

\section{SENSITIVITY ANALYSES}

We conduct several sensitivity analyses to confirm the robustness of our results. First, we impose stricter matching requirements upon our sample. Second, we examine alternative matching algorithms. Third, we exclude firms domiciled in the US, or include only firms domiciled in the EU. Fourth, we calculate for a smaller sample the percentage of shares held by socially responsible investment (SRI) funds and include this variable in our cross-sectional model. Finally, we assess the impact of the individual disclosure components of environmental, social, and governance (as opposed to the composite ESG disclosure measure used in the primary analyses).

\section{Stricter Matching Requirements}

As discussed, our primary analyses match firms exactly on country and sector, and further use propensity score matches on market capitalization and market-to-book ratios. This

18 As an alternative (and more conservative) measure, we subtract from the $3.88 \%$ the estimated reaction for firms operating in industries having the strongest ESG disclosure scores (the value of which is $-1.22 \%$ ). This indicates a net market reaction of $2.66 \%$; which provides a more conservative (though, still positive) measure of the market reaction for the strongest firms. 
matching procedure seeks to isolate the changes in investor expectations reflecting the perceived financial consequences from the announcement of the disclosure regulation (our treatment effect) by differencing away contemporaneously occurring changes in investor expectations that correspond to firms domiciled in the same country, operating in the same sector, and having a similar size and growth profile. That is, the selection of matching criteria trades off the precision of matching the treatment and control firms (which increases the likelihood of differencing away effects unrelated to the regulation we wish to examine) with the reduction in statistical power that typically arises due to more restrictive matching criteria leading to a smaller sample size. Table 3 previously highlighted that our primary matching procedure reduced differences in both market capitalization and market-to-book ratio between the treatment and control firms; however, while differences in market-to-book for the matched pairs were insignificant, those in market capitalization remained significant (see Column (8) of Table 3).

To further ensure that the average effect we document is not driven by remaining differences in firm size across the treatment and control firms, we conduct an additional analysis that further limits the matched firms by restricting the difference between the market capitalization of the treatment and the control firm pairs to no more than $\$ 5$ billion. This leads to a reduced sample of 746 matched pairs, with the following empirical results. Table 6 Panel A (which corresponds to Table 3 Panel A presenting average differences in the market reaction to the three cumulative events) reveals that we continue to find a more negative return for treatment firms $(-1.91 \%$ in Column (1)) relative to control firms $(-1.22 \%$ in Column $(2))$, with the difference of $-0.70 \%$ significantly negative in Column $(3)(t$-stat $=2.75)$. Panel B (which corresponds to Table 3 Panel B presenting average differences controlling for market capitalization and market-to-book) further shows in Column (1) that the coefficient on Treatment 
remains significantly negative $(-0.0098, t$-stat $=2.62)$. Both results confirm a more negative stock price reaction for our treatment firms to the sample events. Finally, Panel C (which corresponds to Table 5) presents the cross-sectional results in Column (1), which are similar to those in our primary analyses. Specifically, we continue to find significantly positive (negative) coefficients on ESG_Discl_Score,Govern_Score,Asset_Owner, and MTB_TopQ (Ind_Max_ESGDiscl, and RegQual); in addition, we find a marginally significantly negative coefficient on NationalReg.

We then conduct a second analysis using an alternative matching algorithm. Our primary analyses include a sample matched on sector (and country, market capitalization, and market-tobook). We alternatively match treatment and control firms using this same algorithm, now matching on GICS industry as opposed to sector. Industry (with 67 classifications) is defined more narrowly than sector (with 10 classifications); accordingly, it provides a more precise economic match of treatment and control firms, but (due to the reduced availability of suitable control firms) also leads to a reduced sample of 857 firm pairs. Results remain consistent with our primary analyses. In Table 6 Panel A, we continue to find in Column (6) a significantly more negative return for the treatment firms $(-0.81 \%, t$-stat $=2.14)$. In Panel $\mathrm{B}$, we continue to find in Column (2) a significantly negative coefficient on Treatment $(-0.0093, t$-stat $=2.92)$. In Panel C, we continue to find in Column (1) significantly positive (negative) coefficients on ESG_Discl_Score and Asset_Owner(RegQual). However, in contrast to our primary analyses, the coefficients on Govern_Score, MTB_TopQ, and Ind_Max_ESGDiscl are now insignificant. In addition, we find that the coefficient on EnvScore is now significantly positive, suggesting firms with worse environmental performance have more negative stock price reactions consistent 
with investors expecting these firms to reveal bad news in the future and having to internalize some of the externalities generated.

Several insights may explain differences between this latter analysis and the findings in the primary analysis. Regarding Ind_Max_ESGDiscl, the country-industry matched sample has higher representation of extractive, industrial and hospitality firms relative to the country-sector match in the primary analysis. ${ }^{19}$ Firms in these industries have higher average nonfinancial disclosure levels (mean ESG_Discl_Score $=33.39$ ) relative to other industries $\left(E S G \_\right.$Discl_Score $\left.=21.24\right)$; however, firms in these industries have similar average industry leader disclosure levels (mean Ind_Max_ESGDiscl $=60.01$ ) as other industries (mean Ind_Max_ESGDiscl $=60.27)$, resulting in smaller differences between the average level of nonfinancial disclosure and the average industry leader's level of nonfinancial disclosure, when representation from these industries is higher. Specifically, for the sample of country-sector matches, the average ESG_Discl_Score is 29.66 and the average Ind_Max_ESGDiscl is 60.57 resulting in an average difference of $30.91(60.57-29.66)$; this difference falls to 24.47 for the sample of country-industry matches, due to the average ESG_Discl_Score increasing to 34.91 and the average Ind_Max_ESGDiscl falling to 59.38 when representation from Oil, Gas and Consumable Fuels, Machinery and Hotels, Restaurants and Leisure, Mining \& Metals increases. Thus, we conjecture that higher representation by firms in industries that have smaller differences between average disclosure levels and industry leader disclosure levels attenuated the negative stock price reactions since there is both less pressure to converge and lower costs to converge to the industry leader's level of disclosure.

19 Specifically, from the country-sector to the country-industry matched sample, representation increased by: $1.41 \%$ for Oil, Gas and Consumable Fuels; $1.3 \%$ for Machinery; $0.77 \%$ for Hotels, Restaurants and Leisure; and 0.63\% for Mining \& Metals. 
Regarding the now insignificant coefficient on Govern_Score, we examine country membership for the country-sector and country-industry samples and find higher representation of US firms in the current country-industry matched sample (67\%) relative to the country-sector matched sample of the primary analysis (52.8\%). As governance concerns likely are lower among investors in US firms, we conjecture that higher representation of strong governance US firms in the country-industry sample attenuates the positive coefficient on Govern_Score in the country-industry matched sample.

\section{Variations in Matching Algorithm}

Next, we implement several alternative matching algorithms. Our matching process in the primary analyses uses replacement. This minimizes the probability of bias as a control firm that appears similar to multiple treatment firms can be used multiple times; thus, the order of matching is irrelevant in a matching process with replacement. In addition, matching with replacement allows us to maximize the available firm pairs in the analysis. To assess the robustness of our results, we alternatively implement a country-sector match without replacement. The sample (as expected) decreases significantly by $69 \%$ to 390 firm pairs. All results remain qualitatively unchanged. The average stock price reaction for treatment firms is more negative by $-0.90 \%$, relative to control firms (significant at the $1 \%$ level). Untabulated cross-sectional results continue to reveal significantly more negative stock price reactions for firms with lower levels of ESG disclosure, governance performance, environmental performance, and shares outstanding held by asset owners.

Given that our matching process identifies similar firms operating in the same sector (or industry), we next assess the sensitivity of our results to firms that are industrially diversified. 
Such firms may result in suboptimal matching, if the market reactions reflect operations in segments not related to that used to match with the treatment firm. Accordingly, we exclude firms with more than $50 \%$ of their sales outside their primary industry. This decreases the sample from 1,249 to 793 matched pairs, with inferences that are similar to our primary analysis. Specifically, treatment firms exhibit a significantly more negative stock price reaction of $0.80 \%$. Cross-sectional analyses again reveal significantly more negative returns for firms with lower levels of ESG disclosure, governance performance, and environmental performance.

Finally, our matching process requires one-to-one matching between treatment and control firms; that is, for each treated firm we match one control firm. Implementing one-tomultiple matching (i.e., having one treatment matched to two or more control firms) can provide better estimates under certain conditions. Our results also are unchanged.

\section{Excluding US Firms}

Table 2 Column (3) reveals that US-domiciled firms comprise almost one-half (48.2\%) of our primary cross-sectional sample. To assess the robustness of our results to this sample characteristic, we next exclude the US firm-pairs, leading to a reduced sample of 647 matched pairs. Table 6 Panel A reveals that we continue to find in Column (9) a significantly more negative market reaction for the treatment firms relative to the control firms (difference of 1.79\%, $t$-stat $=4.12)$. Table 6 Panel B further reveals in Column (3) that the coefficient on Treatment remains significantly negative $(t$-stat $=2.77)$, reflecting an incremental negative market reaction to the event dates of $2.28 \%$ for treatment firms. Both results confirm a more negative reaction for treatment firms, even in a sample excluding US firms. ${ }^{20}$ The relatively

${ }^{20}$ Further, we note that the seemingly larger stock price reaction for the sample of non-US firms appears principally driven by treatment firms. Specifically, the treatment firms now exhibit an average stock price 
more negative stock price reaction for the non-US firm sample potentially reflects that (i) US firms likely have a smaller portion of their operations in the EU (with broader exposure either to US or other international markets) and/or (ii) they have proportionately smaller financial listing in the EU (given the prominence of US capital markets). As such, the US firms likely bear relatively fewer costs from the proposed EU nonfinancial disclosure regulation.

Finally, the cross-sectional analysis for the non-US matched sample, presented in Table 6 Panel C, presents results largely similar to the main analysis. Specifically, Column (3) reveals significantly positive coefficients on ESG_Discl_Score, Govern_Score,Asset_Owner and $M T B \_T o p Q$. The coefficient on Ind_Max_ESGDiscl is now insignificant. In addition, the coefficient on RegQual also is now insignificant, likely reflecting (as a country-level variable) that the coefficient in the main results is heavily influenced by the inclusion of the US firms. Moreover, we now find that the coefficient on Soc_Score is significantly positive, suggesting firms with worse performance on social dimensions have more negative stock price reactions.

\section{Excluding non-EU Firms}

Given that the regulation we examine is implemented in the European Union, one might expect the regulation to have a greater effect on EU firms. For example, there could be stricter enforcement for EU firms, as well as the disclosure regulation being interpreted by investors as a signal of increased regulation in the EU around ESG issues. Accordingly, we next exclude nonEU firms; the sample is now 491 firms. Untabulated results are very similar to those in Table 6 Panel C column (3), where we exclude US firms. Specifically, we again find significantly

reaction of $-3.42 \%$ (see Column (7) of Table 6 Panel A) versus $-2.22 \%$ in the primary control sample (see Column (6) of Table 3 Panel A); a difference of 1.20\%. In contrast, the control firms now exhibit an average price reaction of $-1.63 \%$ (see Column (8) of Table 6 Panel A) versus $-1.51 \%$ in the primary analysis (see Column (7) of Table 3 Panel A), a difference of only $0.11 \%$. 
positive coefficients on ESG_Discl_Score, Govern_Score,Asset_Owner and MTB_TopQ. The coefficients on Ind_Max_ESGDiscl and RegQual are insignificant. The coefficient on Soc_Score is again significantly positive.

\section{Socially Responsible Investment (SRI) Funds}

We investigate the potential for a clientele effect to determine whether the market response differs depending on if investors have specific guidance to source 'green' or 'socially responsible' investments. Socially Responsible Investment (SRI) funds explicitly include nonfinancial considerations in investment decisions. For example, such funds may selectively invest in environmentally-sound firms or firms with good employment practices, or avoid certain industries altogether, such as tobacco, gambling and defense. We expect that firms having higher SRI fund ownership will exhibit more positive stock price reactions, reflecting higher demand for nonfinancial information from such investors. We obtain the listing of all mutual funds classified as SRI funds from Bloomberg, and match these to the Thomson Reuters Mutual Fund Holdings database. Since this latter database consists of US mutual fund holdings of US stocks only, our analysis is limited to US firms. For our cross-sectional sample of US firms ( $N=$ 602) we calculate the percentage of shares held by SRI funds (PctSharesSRI) and include this variable in our cross-sectional model. In untabulated results, we continue to find significantly positive coefficients on ESG_Discl_Score, Govern_Score, Asset_Owner and Ind_Max_ESGDiscl. In addition, the coefficient on PctSharesSRI is significantly positive, consistent with the predicted higher demand for mandatory nonfinancial disclosures from this type of fund. 


\section{Separate Analysis of ESG Disclosure Components}

Our primary analyses measure ESG disclosure as the composite index of disclosure across environmental, social and governance issues. We do not simultaneously include separate variables capturing the individual disclosure levels of environmental, social and governance (as we do with the performance levels - i.e., Govern_Score,Soc_Score, and Environ_Score) due to high multicollinearity across the disclosure levels. Specifically, the univariate correlations between the disclosure variables ranges between 0.51 and 0.82 .

However, to assess their individual impact upon observed market reactions, in untabulated analysis we include each disclosure level individually. We find significantly positive coefficients on both environmental $(0.00024, t$-stat $=2.17)$ and governance disclosure $(0.00047, t$-stat $=2.42)$ levels; this is consistent with the previously discussed positive coefficient on the aggregated disclosure (ESG_Discl_Score). In contrast, we find a positive but insignificant coefficient on the level of social disclosure $(0.00013 t$-stat $=1.33)$.

\section{CONCLUSION}

This paper examines market perceptions of mandated nonfinancial disclosure. Specifically, we examine the equity market reaction to three aggregated events (occurring during 2013-2014), which we assess as increasing the likelihood of regulation mandating nonfinancial disclosure for certain affected firms (principally, those with operations and/or financial listings in the European Union). To identify the market reaction attributable to the regulation, we difference the observed stock returns for our treatment firms with that for control firms matched by country, sector, market capitalization, and price-to-book ratio. This matching process should remove equity market changes attributable to non-regulation factors. 
We first document an on average negative market reaction to these three events. We interpret this as consistent with the equity market anticipating net costs associated with the regulation for most firms. We then conduct cross-sectional analysis to understand the drivers of this negative reaction. We present evidence of a more negative reaction for firms having lower quantity ESG disclosure, lower performance on nonfinancial issues (particularly environmental and governmental performance), or lower proportion of ownership by institutional asset owners. We interpret these results as consistent with the equity market anticipating these future disclosures to reveal worse-than-expected news for firms providing lower quantities of ESG disclosure, future costs to internalize externalities for firms with low ESG performance, and demand for further disclosure beyond that mandated by the directive for firms with a higher percentage of institutional asset owners. These findings are robust to alternative matching procedures for the pairing of treatment and control firms to calculate abnormal returns to the three events, and to excluding US-domiciled firms (the largest country represented in the sample). Overall, we conclude that the equity market perceived that this regulation mandating the provision of nonfinancial information would lead to net costs for affected firms, and that these net costs would be concentrated in firms with weaker nonfinancial disclosure and performance prior to the regulation. In contrast, for firms with strong nonfinancial performance and disclosure investors expect net benefits as evidenced by positive abnormal stock returns around the passage of the regulation. Future research can examine changes in financial performance, and variation in disclosure quality, as the regulation takes effect. 


\section{REFERENCES}

Armstrong, C., M. Barth, A. Jagolinzer, and E. Riedl. 2010. Market reaction to the adoption of IFRS in Europe. The Accounting Review 85 (1): 31-61.

Barth, M., M. McNichols, and P. Wilson. 1997. Factors influencing firms' disclosures about environmental liabilities. Review of Accounting Studies 2 (1): 35-64.

Beatty, A., S. Chamberlain, and J. Magliolo. 1996. An empirical analysis of the economic implications of fair value accounting for investment securities. Journal of Accounting and Economics 22: 43-77.

Bennear, L.S., and S.M. Olmstead. 2008. The impacts of the "right to know": Information disclosure and the violation of drinking water standards. Journal of Environmental Economics and Management 56 (2): 117-130.

Cheng, B., I. Ioannou, and G. Serafeim. 2014. Corporate social responsibility and access to finance. Strategic Management Journal 35, no. 1: 1-23.

Clarkson, P.M., Y. Li, G.D. Richardson, and F.P. Vasvari. 2008. Revisiting the relation between environmental performance and environmental disclosure: An empirical analysis. Accounting, Organizations and Society 33 (4): 303-327.

Cornett, M., Z. Rezaee, and H. Tehranian. 1996. An investigation of capital market reactions to pronouncements on fair value accounting. Journal of Accounting and Economics 22: 119-154.

Dechow, P., A. Hutton, and R. Sloan. 1996. Economic consequences of accounting for stockbased compensation. Journal of Accounting Research 34 (1996): 1-20.

Delmas, M., and M. Toffel. 2008. Organizational responses to environmental demands: opening the black box. Strategic Management Journal 29 (10): 1027-1055.

Delmas, M., M.J. Montes-Sancho, and J.P. Shimshack. 2010. Information disclosure policies: Evidence from the electricity industry. Economic Inquiry 48 (2): 483-498.

Dhaliwal, D., O. Li, A. Tsang, and Y. Yang. 2011. Voluntary nonfinancial disclosure and the cost of equity capital: the initiation of corporate social responsibility reporting. The Accounting Review 86 (1): 59-100.

Dhaliwal, D., S. Radhakrishnan, A. Tsang, and Y. Yang. 2012. Nonfinancial disclosure and analyst forecast accuracy: international evidence on corporate social responsibility disclosure. The Accounting Review 87 (3): 723-759.

Easley, D., and M. O'Hara. 2004. Information and the Cost of Capital. Journal of Finance 59: 1553-1583. 
Eccles, R., M. Krzus, and G. Serafeim. 2011. Market interest in nonfinancial information. Journal of Applied Corporate Finance 23 (4): 113-127.

El Ghoul, S., O. Guedhami, C.C.Y. Kwok, and D.R. Mishra. 2011. Does corporate social responsibility affect the cost of capital? Journal of Banking and Finance 35 (9): 23882406.

Hoi, C., Q. Wu, and H. Zhang. 2013. Is corporate social responsibility (CSR) associated with tax avoidance? Evidence from irresponsible CSR activities. The Accounting Review 88 (6): 2025-2059.

Ioannou, I., and G. Serafeim. 2015. The consequences of mandatory corporate sustainability reporting: Evidence from four countries. Harvard Business School Working Paper.

Jain, P., and Z. Rezaee. 2006. The Sarbanes-Oxley Act of 2002 and capital-market behavior: Early evidence. Contemporary Accounting Research 23 (Fall): 629-654.

Jin, G.Z., and P. Leslie. 2003. The effect of information on product quality: Evidence from restaurant hygiene grade cards. The Quarterly Journal of Economics 118 (2): 409-451.

Joos, P., and E. Leung. 2013. Investor perceptions of potential IFRS adoption in the United States. The Accounting Review 88 (2): 577-609.

Kim, Y., M. Park, and B. Wier. 2012. Is earnings quality associated with corporate social responsibility? The Accounting Review 87 (3): 761-796.

Leuz, C. 2007. Was the Sarbanes-Oxley Act of 2002 really this costly? A discussion of Evidence from Event Returns and Going-Private Decisions. Journal of Accounting \& Economics 44 (2007): 146-175.

Li, H., M. Pincus, and S. O. Rego. 2008. Market reaction to events surrounding the SarbanesOxley Act of 2002 and earnings management. The Journal of Law \& Economics 51: 111-134.

Neu, D., H. Warsame, and K. Pedwell. 1998. Managing public impressions: Environmental disclosures in annual reports. Accounting, Organizations and Society 23 (3): 265-282.

Reid, E., and M. Toffel. 2009. Responding to public and private politics: corporate disclosure of climate change strategies. Strategic Management Journal 30 (11): 1157-1178.

Serafeim, G. 2014. Turning a profit while doing good: aligning sustainability with corporate performance. Governance Studies, Brookings Institution.

Serafeim, G. 2015. Integrated reporting and investor clientele. Journal of Applied Corporate Finance 27, no. 2: 34-51. 
Zhang, I. 2007. Economic consequences of the Sarbanes-Oxley Act of 2002. Journal of Accounting and Economics 44: 74-115. 


\section{APPENDIX A Variable Definitions}

\section{Dependent Variable}

$C A R_{i} \quad$ the cumulative abnormal return for firm $i$ to the aggregated three events identified as affecting the likelihood of passage for the directive mandating increased nonfinancial disclosures in the EU.

\section{Experimental Variables: Firm-Level}

ESG_Discl_Score ${ }_{i}$ a Bloomberg variable that scores from $0-100$ and measures the quantity of ESG disclosures made by firm $i$ in 2013.

Gov_Score $_{i} \quad$ a MSCI variable that scores from $0-10$ and measures the quality of firm $i$ 's governance processes and structure in 2013.

Social_Score $_{i} \quad$ a MSCI variable that scores from 0-10 and measures the performance of firm $i$ in relation to human capital, health and safety, products and services, and supply chain issues in 2013.

Environ_Score $_{i} \quad$ a MSCI variable that scores from $0-10$ and measures the performance of firm $i$ in relation to energy and climate change, natural resource consumption and waste management issues in 2013.

AssetMgr $_{i} \quad$ the percentage of outstanding shares of firm $i$ held by asset managers defined as investment advisors, mutual funds and hedge funds (calculated using 2013 Bloomberg data).

AssetOwner $_{i} \quad$ the percentage of outstanding shares of firm $i$ held by asset owners defined as pension funds, insurance companies and bank trusts (calculated using 2013 Bloomberg data).

$M T B \_T o p Q_{i} \quad$ an indicator variable equaling one if firm $i$ is in the top quartile of marketto-book ratio, and zero otherwise.

MCap_Bot $Q_{i} \quad$ an indicator variable equaling one if firm $i$ is in the bottom quartile of market capitalization, and zero otherwise.

\section{Experimental Variables: Industry-Level}

Ind_MaxESGDiscl ${ }_{m}$ the maximum level of ESG disclosure in 2013 across all firms in firm $i$ 's industry $m$.

Ind_AvgROA $A_{m} \quad$ the average level of ROA in 2013 across all firms in firm $i$ 's industry $m$. 
EnvWeight $_{m} \quad$ an MSCI variable measured in 2013 that ranges from $0-100 \%$ and scores an industry by taking into account both its contribution, relative to all others, to the negative impact on the environment; and the timeline within which we expect that financial risk for companies in the industry would be expected to materialize.

\section{Experimental Variables: Country-Level}

CommonLaw $_{k} \quad$ an indicator variable equaling 1 if country $k$ (the country of firm $i$ 's domicile) is a common law country, and zero otherwise.

$\operatorname{RegQual}_{k} \quad$ country $k$ 's 2013 World Bank rating of its regulatory quality, which captures perceptions of the ability of the government to formulate and implement sound policies and regulations that permit and promote private sector development.

NationalReg $_{k} \quad$ an indicator variable equaling 1 if country $k$ (the country of firm $i$ 's domicile) already mandates similar nonfinancial disclosures in 2013 as those being mandated in the examined directive, and zero otherwise. 


\section{TABLE 1 \\ Sample Selection}

Panel A. Identification of Available Firms

Bloomberg population (for 2014)

\# of firms

Less: South African firms

15,133

260

Less: missing required information for matching

2,711

Available firms

12,162

Panel B. Matching of Treatment and Control Firms

Available firms

\begin{tabular}{rrr} 
Treatment & Control & Total \\
\hline 2,417 & 9,745 & 12,162 \\
364 & 7,692 & 8,056 \\
\hline $\mathbf{2 , 0 5 3}$ & $\mathbf{2 , 0 5 3}$ & $\mathbf{4 , 1 0 6}$
\end{tabular}

Matched Sample: Univariate Analysis

\section{Country-Sector Matching}

Less: missing cross-sectional data information

Matched Sample: Cross-sectional Analysis

\begin{tabular}{rrr}
804 & 804 & 1,608 \\
\hline $\mathbf{1 , 2 4 9}$ & $\mathbf{1 , 2 4 9}$ & $\mathbf{2 , 4 9 8}$ \\
\hline \hline
\end{tabular}

This table presents the sample selection process. Panel A presents the available firms. Panel B presents the derivation of the univariate and cross-sectional treatment and control firm samples derived using the country-sector matching. 
TABLE 2

Distribution of Observations

\begin{tabular}{c|c|c}
$\begin{array}{c}\text { Before } \\
\text { matching }\end{array}$ & After & Cross-Sectional \\
$(N=2,417)$ & matching & After Matching \\
$(N=2,053)$ & \multicolumn{2}{c}{$(N=1,249)$} \\
Unique & Unique & Unique \\
Firms $\quad \%$ & Firms $\quad \%$ & Firms $\quad \%$ \\
\hline$(1)$ & $(2)$ &
\end{tabular}

Panel A. Frequency by Country

\begin{tabular}{|c|c|c|c|c|c|c|}
\hline Australia & 77 & 3.2 & 75 & 3.6 & 61 & 4.9 \\
\hline Austria & 49 & 2.0 & 10 & 0.5 & 4 & 0.3 \\
\hline Belgium & 16 & 0.6 & 4 & 0.2 & 3 & 0.2 \\
\hline Bermuda & 7 & 0.3 & 3 & 0.2 & 3 & 0.2 \\
\hline Brazil & 4 & 0.1 & 0 & 0.0 & 0 & 0.0 \\
\hline Canada & 5 & 0.2 & 0 & 0.0 & 0 & 0.0 \\
\hline Chile & 1 & 0.1 & 0 & 0.0 & 0 & 0.0 \\
\hline China & 5 & 0.2 & 0 & 0.0 & 0 & 0.0 \\
\hline Denmark & 55 & 2.2 & 40 & 1.9 & 15 & 1.2 \\
\hline Finland & 77 & 3.2 & 56 & 2.7 & 14 & 1.1 \\
\hline France & 150 & 6.2 & 123 & 6.0 & 54 & 4.3 \\
\hline Germany & 242 & 10.0 & 222 & 10.7 & 55 & 4.4 \\
\hline Greece & 17 & 0.7 & 0 & 0.0 & 0 & 0.0 \\
\hline Hong Kong & 3 & 0.1 & 0 & 0.0 & 0 & 0.0 \\
\hline Indonesia & 2 & 0.1 & 0 & 0.0 & 0 & 0.0 \\
\hline Ireland & 21 & 0.9 & 3 & 0.2 & 1 & 0.1 \\
\hline Israel & 2 & 0.1 & 0 & 0.0 & 0 & 0.0 \\
\hline Italy & 131 & 5.4 & 109 & 5.3 & 35 & 2.8 \\
\hline Japan & 80 & 3.3 & 77 & 3.7 & 69 & 5.5 \\
\hline South Korea & 2 & 0.1 & 0 & 0.0 & 0 & 0.0 \\
\hline Luxembourg & 12 & 0.5 & 3 & 0.2 & 0 & 0.0 \\
\hline Malaysia & 1 & 0.1 & 0 & 0.0 & 0 & 0.0 \\
\hline Mexico & 2 & 0.1 & 0 & 0.0 & 0 & 0.0 \\
\hline Netherlands & 68 & 2.8 & 55 & 2.7 & 21 & 1.7 \\
\hline Norway & 69 & 2.9 & 59 & 2.9 & 13 & 1.0 \\
\hline Portugal & 34 & 1.4 & 9 & 0.4 & 1 & 0.1 \\
\hline Russia & 3 & 0.1 & 0 & 0.0 & 0 & 0.0 \\
\hline Singapore & 4 & 0.2 & 0 & 0.0 & 0 & 0.0 \\
\hline Spain & 78 & 3.2 & 20 & 1.0 & 10 & 0.8 \\
\hline Sweden & 122 & 5.1 & 113 & 5.8 & 36 & 2.9 \\
\hline Switzerland & 19 & 0.8 & 14 & 0.7 & 10 & 0.8 \\
\hline Turkey & 1 & 0.1 & 0 & 0.0 & 0 & 0.0 \\
\hline United Kingdom & 436 & 18.0 & 436 & 21.1 & 242 & 19.4 \\
\hline United States & 622 & 25.7 & 622 & 30.1 & 602 & 48.2 \\
\hline Total & 2,417 & 100.0 & 2,053 & 100.0 & 1,249 & 100.0 \\
\hline
\end{tabular}




\begin{tabular}{c|c|cc}
$\begin{array}{c}\text { Before } \\
\text { matching }\end{array}$ & After & Cross-Sectional \\
$(N=2,417)$ & matching & After Matching \\
$(N=2,053)$ & $(N=1,249)$ \\
Unique & Unique & Unique \\
Firms $\quad \%$ & Firms $\quad \%$ & Firms & $\%$ \\
\hline$(1)$ & $(2)$ & \multicolumn{2}{c}{ \% }
\end{tabular}

Panel B. Frequency by Sector

\begin{tabular}{lrr|rr|rr} 
Energy & 125 & 5.2 & 99 & 4.8 & 72 & 5.8 \\
Materials & 222 & 9.2 & 143 & 7.0 & 101 & 8.1 \\
Industrials & 569 & 23.5 & 511 & 24.8 & 223 & 17.9 \\
Consumer Discretionary & 449 & 18.6 & 410 & 19.9 & 243 & 19.5 \\
Consumer Staples & 164 & 6.8 & 115 & 5.6 & 77 & 6.2 \\
Health Care & 139 & 5.8 & 122 & 5.9 & 87 & 7.0 \\
Financials & 338 & 14.0 & 305 & 14.8 & 231 & 18.5 \\
Information Technology & 288 & 12.0 & 266 & 13.2 & 148 & 11.9 \\
Telecommunication Services & 39 & 1.6 & 17 & 0.8 & 13 & 1.0 \\
Utilities & 84 & 3.5 & 65 & 3.2 & 54 & 4.3 \\
Total & $\mathbf{2 , 4 1 7}$ & $\mathbf{1 0 0 . 0}$ & $\mathbf{2 , 0 5 3}$ & $\mathbf{1 0 0 . 0}$ & $\mathbf{1 , 2 4 9}$ & $\mathbf{1 0 0 . 0}$ \\
\hline
\end{tabular}

This table presents the frequency distribution of observations by country (Panel A) and sector (Panel B). Within each panel, Column (1) presents the distribution of the treatment observations before imposing any data requirements. Column (2) presents the distribution of the treatment and matched control observations before imposing any cross-sectional data requirements. Column (3) presents the distribution of the treatment and matched control observations after imposing the cross-sectional data requirements. 
Panel A. Average Effects

TABLE 3

Univariate Analysis

\begin{tabular}{|c|c|c|c|c|c|c|c|c|}
\hline & \multicolumn{2}{|c|}{ Before Matching } & \multicolumn{3}{|c|}{ After Matching } & \multicolumn{3}{|c|}{ Cross-Sectional Analyses } \\
\hline & $\begin{array}{c}\text { Treatment } \\
\text { Sample } \\
(N=2,417)\end{array}$ & $\begin{array}{c}\text { Control } \\
\text { Sample } \\
(N=9,745)\end{array}$ & $\begin{array}{c}\text { Treatment } \\
\text { Sample } \\
(N=\mathbf{2 , 0 5 3 )}\end{array}$ & $\begin{array}{c}\text { Control } \\
\text { Sample } \\
(N=\mathbf{2 , 0 5 3 )}\end{array}$ & Difference & $\begin{array}{c}\text { Treatment } \\
\text { Sample } \\
(N=\mathbf{1 , 2 4 9})\end{array}$ & $\begin{array}{c}\text { Control } \\
\text { Sample } \\
(N=\mathbf{1 , 2 4 9})\end{array}$ & Difference \\
\hline & (1) & (2) & (3) & (4) & $(5)=(3)-(4)$ & (6) & (7) & $(8)=(6)-(7)$ \\
\hline $\begin{array}{l}\text { Cumulative 5- } \\
\text { day return } \\
\text { across } 3 \text { events }\end{array}$ & -0.0256 & -0.0260 & -0.0250 & -0.0171 & $\begin{array}{c}-0.0079 \\
(2.74 * *)\end{array}$ & -0.0222 & -0.0151 & $\begin{array}{l}-\mathbf{0 . 0 0 7 1} \\
(\mathbf{2 . 6 0} * *)\end{array}$ \\
\hline $\begin{array}{l}\text { Market } \\
\text { Capitalization }\end{array}$ & 7,782 & 1,538 & 10,009 & 6,777 & $\begin{array}{c}3,232 \\
(2.51 * *)\end{array}$ & 12,556 & 9,279 & $\begin{array}{c}3,227 \\
(2.77 * *)\end{array}$ \\
\hline $\begin{array}{l}\text { Market-to- } \\
\text { Book }\end{array}$ & 2.16 & 1.73 & 2.46 & 2.38 & $\begin{array}{c}0.08 \\
(1.13)\end{array}$ & 2.67 & 2.59 & $\begin{array}{r}0.08 \\
(1.02)\end{array}$ \\
\hline
\end{tabular}

Panel B. Average Effects Controlling for Market Capitalization and Market-to-Book

\begin{tabular}{|c|c|c|c|}
\hline \multirow[b]{2}{*}{ Variable } & \multirow{2}{*}{$\begin{array}{l}\text { Predicted } \\
\text { Sign }\end{array}$} & $\begin{array}{c}\text { Sample } \\
\text { After Matching } \\
\end{array}$ & $\begin{array}{c}\text { Sample for } \\
\text { Cross-Sectional Analyses } \\
\end{array}$ \\
\hline & & Coefficient (t-statistic) & Coefficient (t-statistic) \\
\hline & & $(1)$ & $(2)$ \\
\hline Intercept & $?$ & $-0.0714(1.80 *)$ & $-0.0496(2.35 * *)$ \\
\hline Treatment & $+1-$ & $-0.0101(2.68 * *)$ & $-0.0120(2.72 * *)$ \\
\hline $\log (M C a p)$ & $+1-$ & $0.0025(1.72 *)$ & $0.0040(1.89 *)$ \\
\hline$M T B$ & $+1-$ & $0.0010(2.81 * *)$ & $0.0016(4.93 * * *)$ \\
\hline $\begin{array}{l}N \\
\text { Adj-R }\end{array}$ & & $\begin{array}{l}4,106 \\
0.020\end{array}$ & $\begin{array}{l}2,498 \\
0.015\end{array}$ \\
\hline
\end{tabular}


This table presents univariate comparisons.

Panel A presents average effects of the aggregated market reactions to events affecting passage of the mandated nonfinancial disclosures in the European Union. Columns (1) and (2) present the treatment $(N=2,417)$ and control $(N=9,745)$ samples prior to matching. Columns (3) and (4) present the treatment $(N=2,053)$ and control $(N=2,053)$ samples used in the univariate analysis after matching. Columns (6) and (7) present the treatment $(N=1,249)$ and control $(N=1,249)$ samples used in the cross-sectional analyses after matching. Columns (5) and (8) present differences between the matched treatment and control samples. The first row presents the average cumulative 5-day raw return to the aggregated three events identified as affecting the likelihood of passage for the directive mandating increased nonfinancial disclosures in the EU. The second row presents the average market capitalization, in $\$$ millions at fiscal year-end. The third row presents the average market-to-book ratio, as of the end of the fiscal year.

Panel B presents average effects controlling for (i) $\log (\mathrm{MCap}$ ) (the $\log$ of market capitalization in $\$$ millions at fiscal year-end) and (ii) $M T B$ (the market-to-book ratio as of the fiscal year-end). The experimental variable is Treatment, an indicator variable equal to one if the firm is required to adopt the mandated nonfinancial disclosures in the EU (i.e., a treatment firm), and zero otherwise (i.e., a control firm). Standard errors are clustered by country.

$* * *, * *, *$ represent significance for two-tailed tests of differences. $t$-statistics are shown in parentheses. 
TABLE 4

Descriptive Statistics

Panel A. Descriptive Data $(N=1,249)$

\begin{tabular}{|c|c|c|c|c|c|c|c|}
\hline Variable & Mean & Median & Std Dev & Variable & Mean & Median & Std Dev \\
\hline$C A R$ & -0.007 & -0.006 & 0.088 & MCAP_BotQ & 0.250 & 0.000 & 0.433 \\
\hline ESG_Discl_Score & 30.187 & 27.273 & 16.742 & Ind_Max_ESGDiscl & 56.885 & 59.504 & 8.818 \\
\hline Govern_Score & 6.429 & 6.400 & 2.690 & Ind_Avg_ROA & 5.069 & 5.367 & 2.369 \\
\hline Soc_Score & 4.627 & 4.500 & 1.781 & EnvWeight & 35.358 & 32.000 & 20.293 \\
\hline Environ_Score & 5.473 & 5.400 & 2.205 & CommonLaw & 0.728 & 1.000 & 0.445 \\
\hline Asset_Mgr & 75.979 & 86.635 & 24.157 & RegQual & 1.413 & 1.258 & 0.282 \\
\hline Asset_Owner & 3.884 & 3.086 & 6.115 & NationalReg & 0.055 & 0.000 & 0.229 \\
\hline$M T B \_T o p Q$ & 0.250 & 0.000 & 0.433 & & & & \\
\hline
\end{tabular}

Panel B. Correlations $(N=1,249)$

\begin{tabular}{|c|c|c|c|c|c|c|c|c|c|c|c|c|c|c|}
\hline Variable & (1) & $(2)$ & (3) & (4) & (5) & $(6)$ & $(7)$ & (8) & (9) & (10) & (11) & (12) & (13) & (14) \\
\hline (1) $C A R$ & 1.000 & & & & & & & & & & & & & \\
\hline (2) ESG_Discl_Score & 0.032 & 1.000 & & & & & & & & & & & & \\
\hline (3) Govern_Score & 0.108 & 0.013 & 1.000 & & & & & & & & & & & \\
\hline (4) Soc_Score & 0.001 & 0.156 & 0.041 & 1.000 & & & & & & & & & & \\
\hline (5) Environ_Score & 0.034 & 0.080 & -0.021 & 0.118 & 1.000 & & & & & & & & & \\
\hline (6) Asset_Mgr & 0.073 & -0.175 & 0.140 & -0.151 & -0.017 & 1.000 & & & & & & & & \\
\hline (7) Asset_Owner & 0.067 & 0.091 & 0.009 & -0.009 & 0.025 & -0.064 & 1.000 & & & & & & & \\
\hline (8) MTB_TopQ & 0.064 & -0.082 & 0.076 & -0.044 & 0.064 & 0.103 & -0.023 & 1.000 & & & & & & \\
\hline (9) MCAP_BotQ & -0.012 & -0.007 & -0.017 & 0.012 & -0.115 & -0.122 & -0.086 & -0.090 & 1.000 & & & & & \\
\hline (10) Ind_Max_ESGDiscl & $-\mathbf{0 . 0 8 5}$ & 0.103 & 0.018 & 0.043 & -0.224 & -0.038 & 0.063 & -0.082 & -0.163 & 1.000 & & & & \\
\hline (11) Ind_Avg_ROA & 0.056 & 0.000 & 0.019 & $-\mathbf{0 . 0 8 9}$ & 0.083 & 0.062 & -0.039 & 0.268 & -0.039 & -0.114 & 1.000 & & & \\
\hline (12) EnvWeight & 0.018 & 0.117 & 0.181 & 0.101 & -0.231 & -0.072 & 0.007 & -0.050 & -0.025 & 0.269 & -0.033 & 1.000 & & \\
\hline (13) CommonLaw & 0.033 & -0.250 & 0.104 & -0.219 & -0.090 & 0.548 & $-\mathbf{0 . 1 3 0}$ & 0.187 & 0.033 & -0.090 & 0.038 & -0.047 & 1.000 & \\
\hline (14) RegQual & -0.087 & 0.126 & 0.049 & 0.135 & 0.071 & -0.092 & -0.022 & 0.039 & 0.272 & -0.039 & 0.026 & -0.004 & 0.093 & 1.000 \\
\hline (15) NationalReg & -0.024 & 0.101 & -0.047 & 0.163 & 0.065 & -0.261 & -0.135 & -0.067 & -0.042 & 0.042 & 0.038 & 0.049 & -0.395 & -0.106 \\
\hline
\end{tabular}

This table presents descriptive statistics. The sample $(N=1,249)$ is observations for the cross-sectional analyses using the treatment observations matched on country-sector. Panel A presents descriptive data (means, medians, and standard deviations). Panel B presents correlations; bolded numbers represent significance at 5\% or higher level. All variables are defined in Appendix A. 


\section{TABLE 5}

\section{Cross-Sectional Analyses}

\begin{tabular}{cccc} 
Variable & $\begin{array}{c}\text { Predicted } \\
\text { Sign }\end{array}$ & \multicolumn{2}{c}{ Country-Sector Match } \\
Coefficient & $\boldsymbol{t}$-stat \\
\hline Intercept & $?$ & 0.01955 & $(0.49)$
\end{tabular}

\section{Firm-Level Variables:}

$\begin{array}{lccl}\text { ESG_Discl_Score } & + \text { I- } & 0.00030 & (2.53) * * \\ \text { Govern_Score } & +/- & 0.00311 & (2.71) * * \\ \text { Soc_Score } & +/- & 0.00094 & (0.77) \\ \text { Environ_Score } & +/- & 0.00087 & (0.81) \\ \text { Asset_Mgr } & + & 0.00019 & (1.13) \\ \text { Asset_Owner } & + & 0.00104 & (2.70) * * \\ \text { MTB_TopQ } & + & 0.00925 & (1.61) * \\ \text { MCAP_BotQ } & - & 0.00537 & (0.89)\end{array}$

\section{Industry-Level Variables:}

$\begin{array}{llrl}\text { Ind_Max_ESGDiscl } & - & -0.00090 & (2.60) \\ \text { Ind_Avg_ROA } & - & 0.00134 & (1.21) \\ \text { EnvWeight } & - & 0.00013 & (0.51)\end{array}$

\section{Country-Level Variables:}

\begin{tabular}{lcrc} 
CommonLaw & + & 0.00254 & $(0.21)$ \\
RegQual & - & -0.03484 & $(2.42) * *$ \\
NationalReg & $+/-$ & -0.00310 & $(0.13)$ \\
& & \multicolumn{2}{c}{1,249} \\
$N$ & & \multicolumn{2}{c}{1,249}
\end{tabular}

This table presents results of our multivariate analyses examining the cross-sectional determinants of the market reactions to events affecting passage of the mandated nonfinancial disclosures in the European Union.

The dependent variable is $C A R_{i}$, the cumulative abnormal return for firm $i$ to the aggregated three events identified as affecting the likelihood of passage for the directive mandating increased nonfinancial disclosures in the EU. Each firm $i$ return is adjusted for that from a matched control firm. Matching is done by country and sector, as well as a propensity score match using the market-to-book ratio and market capitalization.

All experimental variables are defined in Appendix A.

$* * *, * *, *$ represent significance for the indicated one-tailed or two-tailed tests. Standard errors are clustered by country. 
TABLE 6

Sensitivity Analyses: Alternative Matching and Samples

Country-Sector Match with Size Difference Minimization

Country-Industry Match

Country-Sector Match Excluding US Observations

Panel A. Average Effects

\begin{tabular}{|c|c|c|c|c|c|c|c|c|c|}
\hline & $\begin{array}{c}\text { Treatment } \\
\text { Sample } \\
(N=746)\end{array}$ & $\begin{array}{c}\text { Control } \\
\text { Sample } \\
(N=746)\end{array}$ & Difference & $\begin{array}{c}\text { Treatment } \\
\text { Sample } \\
(N=857)\end{array}$ & $\begin{array}{c}\text { Control } \\
\text { Sample } \\
(N=857)\end{array}$ & Difference & $\begin{array}{c}\text { Treatment } \\
\text { Sample } \\
(N=647)\end{array}$ & $\begin{array}{l}\text { Control } \\
\text { Sample } \\
(N=647)\end{array}$ & Difference \\
\hline & (1) & (2) & (3) & (4) & $(5)$ & (6) & (7) & (8) & (9) \\
\hline $\begin{array}{l}\text { Cumulative 5-day } \\
\text { raw return } \\
\text { across } 3 \text { events }\end{array}$ & -0.0191 & -0.0122 & $\begin{array}{c}-\mathbf{0 . 0 0 7 0} \\
(2.75 * * *)\end{array}$ & -0.0194 & -0.0113 & $\begin{array}{l}-0.0081 \\
(2.14 * *)\end{array}$ & -0.0342 & -0.0163 & $\begin{array}{c}-0.0179 \\
(4.12 * * *)\end{array}$ \\
\hline Market Capitalization & 12,261 & 9,646 & $\begin{array}{c}2,651 \\
(2.01 * *)\end{array}$ & 12,108 & 8,223 & $\begin{array}{c}3,885 \\
(2.92 * *)\end{array}$ & 12,231 & 5,943 & $\begin{array}{c}6,288 \\
(5.63 * * *)\end{array}$ \\
\hline Market-to-Book & 2.32 & 2.23 & $\begin{array}{c}0.09 \\
(1.04)\end{array}$ & 2.72 & 2.62 & $\begin{array}{c}0.10 \\
(1.11)\end{array}$ & 2.31 & 2.14 & $\begin{array}{c}0.17 \\
(\mathbf{1 . 1 8})\end{array}$ \\
\hline
\end{tabular}

Panel B. Average Effects Controlling for Market Capitalization and Market-to-Book

\begin{tabular}{lcc|c|c} 
Variable & $\begin{array}{c}\text { Predicted } \\
\text { Sign }\end{array}$ & Coefficient $(\boldsymbol{t}$-statistic) & Coefficient $(\boldsymbol{t}$-statistic) & Coefficient $(\boldsymbol{t}$-statistic) \\
\hline & & $(1)$ & $(2)$ & $(3)$ \\
Intercept & $?$ & $-0.0080(1.34)$ & $-0.0164(0.56)$ & $-0.0358(1.70 *)$ \\
Treatment & $+/-$ & $-\mathbf{0 . 0 0 9 8}(\mathbf{2 . 6 2} * *)$ & $-\mathbf{0 . 0 0 9 3}(\mathbf{2 . 8 1 * * )}$ & $-\mathbf{0 . 0 2 2 8}(\mathbf{2 . 7 7} * *)$ \\
Log $($ MCap $)$ & $+/-$ & $0.0009(0.62)$ & $0.0006(0.48)$ & $0.0025(1.09)$ \\
$M T B$ & $+/-$ & $0.0013(1.91 *)$ & $0.0003(1.89 *)$ & $0.0012(1.66)$ \\
$N$ & & 1,492 & 1,714 & 1,294 \\
$A d j-R^{2}$ & & 0.018 & 0.010 & 0.015
\end{tabular}


Country-Sector Match with

Size Difference Minimization

Country-Industry Match

Country-Sector Match

Excluding US Observations

Panel C. Multivariate Analyses

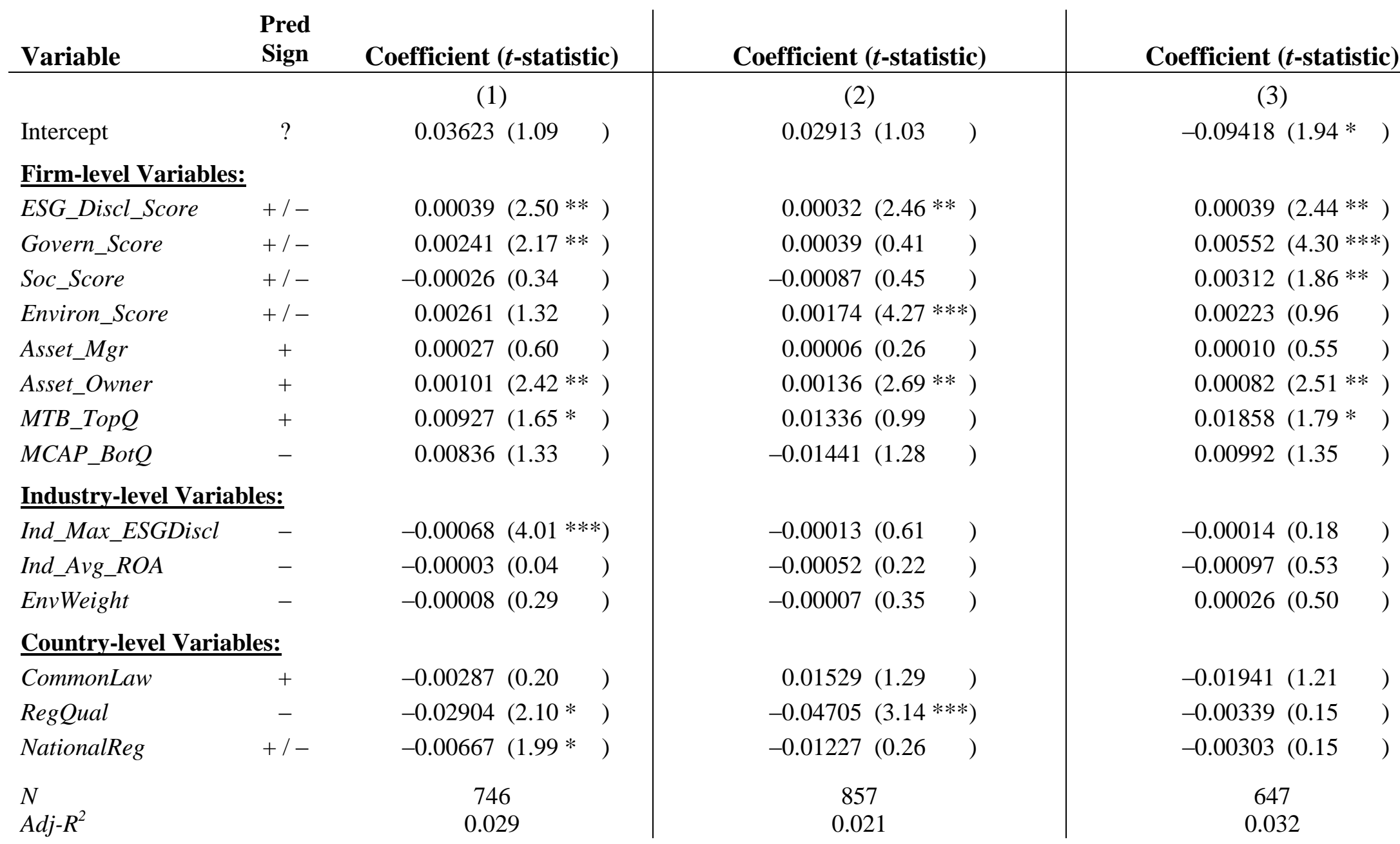


This table presents sensitivity analyses. Across all panels, we examine three alternative samples. First, we present a country-sector match with a more restrictive size difference minimization; the treatment and control samples each include $N=746$ (total $N=1,492$ ). Second, we present a country-industry match, which is more restrictive than matching on sector. The treatment and control samples each include $N=857$ (total $N=1,714$ ). Third, we exclude observations domiciled in the US, the country having the highest representation in our sample. The treatment and control samples each include $N=647$ (total $N=1,294$ ).

Panel A presents average effects of the aggregated market reactions to events affecting passage of the mandated nonfinancial disclosures in the European Union across the three alternative treatment and control samples. Columns (1) - (3) present comparisons across the country-sector match with more restrictive size difference minimization; Columns (4) - (6) present comparisons across the country-industry match; and Columns (7) - (9) present comparisons excluding US observations. The first row presents the average cumulative 5-day raw return to the aggregated three events identified as affecting the likelihood of passage for the directive mandating increased nonfinancial disclosures in the EU. The second row presents the average market capitalization, in $\$$ millions at fiscal yearend. The third row presents the average market-to-book ratio, as of the end of the fiscal year.

Panel B presents average effects controlling for (i) $\log (\mathrm{MCap}$ ) (the $\log$ of market capitalization in $\$$ millions at fiscal year-end) and (ii) $M T B$ (the market-to-book ratio as of the fiscal year-end). The experimental variable is Treatment, an indicator variable equal to one if the firm is required to adopt the mandated nonfinancial disclosures in the EU (i.e., a treatment firm), and zero otherwise (i.e., a control firm). Standard errors are clustered by country.

Panel C presents the multivariate results. Standard errors are clustered by country.

***,**, * represent significance for the indicated one or two-tailed tests of differences. $t$-statistics are shown in parentheses. All variables are defined in Appendix A. 